\title{
IDENTIFYING AND PRIORITIZING THE SELECTION CRITERIA OF APPROPRIATE REPAIR AND MAINTENANCE METHODS FOR COMMERCIAL BUILDINGS
}

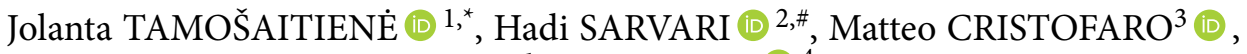 \\ Daniel W. M. CHAN (1D 4 \\ ${ }^{1}$ Institute of Sustainable Construction, Faculty of Civil Engineering, Vilnius Gediminas Technical University, \\ Vilnius, Lithuania \\ ${ }^{2}$ Department of Civil Engineering, Isfahan (Khorasgan) Branch, Islamic Azad University, Isfahan, Iran \\ ${ }^{3}$ Department of Management and Law, University of Rome "Tor Vergata", Rome, Italy \\ ${ }^{4}$ Department of Building and Real Estate, The Hong Kong Polytechnic University, Hung Hom, Kowloon, \\ Hong Kong, China
}

Received 26 November 2020; accepted 27 April 2021

\begin{abstract}
All buildings require Repair and Maintenance (R\&M) in their life cycle period. However, if R\&M activities are not carried out properly, deterioration will occur, service life of buildings will be reduced, and maintenance costs will increase. Hence, selecting the appropriate R\&M methods is pivotal, especially for developing countries, such as Iran, which are featured by highly constrained resources. The present study aims to identify and prioritize the main criteria for selecting the suitable R\&M methods for Commercial Buildings (CBs), which is considered as a profound challenge for the Architecture, Engineering and Construction/Facility Management (AEC/FM) industry. A total of 20 senior experts in the AEC/FM industry and CBs in Iran were invited to participate in a Delphi survey to solicit their perceptions and opinions on the selection criteria. The total number of individual criteria identified is 16, which are further divided into five categories: human resources, flexibility and technical capability, risks, cost of maintenance, together with facilities and technology. Then, the Fuzzy Analytic Hierarchy Process (FAHP) technique was applied to prioritize the identified criteria. Among the 5 main selection criteria, the cost of maintenance is the most important criterion for selecting appropriate R\&M methods for CBs whereas the criterion of human resources (HR) was recognized as the least important.
\end{abstract}

Keywords: repair and maintenance, life cycle costs, fuzzy approaches, commercial buildings.

\section{Introduction}

Buildings are the most valuable assets of countries because they provide people with shelter and facilities for work and leisure activities. However, obsolescence of buildings caused by time requires the implementation of Repair and Maintenance (R\&M) activities, and this becomes an invaluable process in retaining the value and quality of a building (Lam et al., 2010; Shen, 1997). As a consequence, governments all over the World spend a considerable amount of funds each year, around $50 \%$ of the total turnover of the Architecture, Engineering and Construction/Facility Management (AEC/FM) industry (Lateef, 2009), toward R\&M projects (Al-Arjani, 2002; Grussing, 2014). From that, scholars have been increasingly focused on identifying the appropriate maintenance and repair methods that can lower the R\&M costs of buildings, e.g., Mangano and De Marco (2014); this is because employing a suitable R\&M practice considerably reduces the cost of maintenance and repair (Suweero et al., 2017). Among the vast array of building typologies, Commercial Buildings (CBs) are necessary for the future development of cities due to the unprecedented population migration towards them (Bagaeen, 2007); however, CBs are equipped with a wide range of facilities and their maintenance is essential to meet the requirements in the long run (Lai, 2015; Nourelfath et al., 2016). With the increasing number of CBs, the issues associated with their R\&M rises, and this creates the need for seeking appropriate criteria and R\&M methods to offset a portion of the costs (Ruparathna et al., 2018).

In this regard, the broadness of R\&M methods (Roue's formula system, the priority category matrix, point

${ }^{*}$ Corresponding author. E-mail: jolanta.tamosaitiene@vilniustech.lt

\#Corresponding author. E-mail: h.sarvari@khuisf.ac.ir

Copyright (C) 2021 The Author(s). Published by Vilnius Gediminas Technical University

This is an Open Access article distributed under the terms of the Creative Commons Attribution License (https://creativecommons.org/licenses/by/4.0/), which permits unrestricted use, distribution, and reproduction in any medium, provided the original author and source are credited. 
accumulation system, multi-attribute approach and Alani method) and the existence of many criteria (e.g., ability to respond, long-term effect, etc.) makes it harder to choose a particular method for R\&M (for an account of these methods and criteria see, for example, Alani et al., 2002; Martínez et al., 2013; Wieczorek et al., 2019). On that point, Besiktepe et al. (2020) tried developing a Multi-Criteria Decision-Making Approach for the identification of the criteria for building maintenance decisions in facility management. In doing so, they administered a questionnaire to 127 facility managers in Colorado and found that criteria such as "Health and Safety", "Code Compliance", and "Condition" have higher importance compared to "Cost" and "Funding Availability". Similarly, Chua et al. (2014) tried prioritizing criteria of procurement selection for building maintenance projects; in their study, respondents were employees of the maintenance and facilities' maintenance management department of one public University in Malaysia and found that "Price Competition" was the most important criterion for procurement of the R\&M decision.

However, the above-cited studies did not consider some important criteria, such as "Human Resources" and "Flexibility and Technical Capability", nor did they consider the case of Iran, showcased by highly constrained and unequally distributed resources (Ledford \& Lynch, 2019). In this context, other studies tried elaborating tools for easing maintenance management of facilities in Iran (Amani et al., 2012, 2013; Motamed \& Majrouhi, 2018), but, no-one aimed at prioritizing the criteria for selecting appropriate R\&M methods for CBs. Therefore, the aim of this study, implemented in the Iranian context, is to fill the following gap: identifying and prioritizing the selection criteria of appropriate R\&M methods for CBs. Answering this question would advance current related literature, which has fragmentarily highlighted the existence of some technical and managerial matters (e.g., the effect of climate, design and materials' choice, personnel of AEC/FM industry, managerial systems and financial systems) connected with R\&M of buildings in developing countries (Wall, 1993; Olanrewaju \& Abdul-Aziz, 2014), but has not provided insights on how to specifically evaluate and compare R\&M methods (Sodnagi et al., 2014). Yet, the CBs' literature has been mainly focused on investigating returns on investments (Baum, 2009; Duca \& Ling, 2020; Geltner et al., 2001; Ghent et al., 2019), without being interested in R\&M methods and their assessment criteria.

In order to fill the above-mentioned gaps, a total of 20 experts in the AEC/FM industry and CBs in Iran - still considered as a developing country (United Nations, 2020) were invited to participate in a Delphi survey to solicit their perceptions and opinions on R\&M methods to be implemented in CBs and the criteria to assess them. Through comparison with similar studies, heterogeneity of criteria emerges among developed and developing countries, while there seems to be a certain degree of homogeneity when looking at the studies conducted in Iran and developing countries, where cost of maintenance is the main method chosen by decision makers in selecting how to repair and maintain a building. Despite this result, clearly connected to country system features that should be further explored by future research, decision makers of R\&M activities are recommended to systematically consider all five identified categories due to the fact that slightly higher R\&M activities and/or suppliers can drive toward more effective results and a reduction of costs for future interventions.

The theoretical background at the basis of this research, especially the literature related to previously-used criteria for assessing R\&M methods, is reported in Section 1. Then, in Section 2 the Delphi study and Fuzzy Analytic Hierarchy Process (FAHP) methodologies are introduced. Subsequently, in Section 3 results of the research are presented. In Section 4 discussion are presented. Finally, in the last section implications for theory and practice, together with limitations, are debated.

\section{Theoretical background}

\subsection{Repair and maintenance for buildings}

Urbanized areas are increasingly developed with housing estates. Further to their design and construction, the services provided for managing estates' facilities are crucial to the living quality of numerous inhabitants. One of the most common metrics Facility Condition Index (FCI): related to the built environment conditions (Re Cecconi et al., 2019). For the comprehensive evaluation (Yuan et al., 2019) key success factors can indicated. In this regard, it is not sufficient to assess facility maintenance services through key success factors such as: general management (GM), security (S), cleaning (C), and building characteristics (B) (Lai, 2011). Indeed, R\&M is a core activity that should be developed to efficiently manage the building costs. Indeed, prior studies revealed that the adoption of R\&M activities increases the operational costs but, when performed with adequate periodicity, it allows maintaining the buildings' performance at high standards and reducing building costs linked to carelessness (Ferreira et al., 2021).

The idea of establishing a CB in a city reflects its physical and social development (Oprea \& Popescu, 2008). The main objective of all CBs is to create a pleasant environment, where their facilities provide high-quality services for customers. As depicted by Bond et al. (2007), many of the modern western societies combine CBs to increase their profits. In some cases, the CBs are even considered as recreational shopping centers (Pivo \& Fisher, 2011). Hence, without proper maintenance, these centers will become degraded and, in some cases, lead to dramatic financial losses (Daibing \& Zeng, 2014), as happened with the Plasko building in Tehran, Iran, or the CBs of Yemnaya Vishnia in Russia. In contrast, it has been demonstrated, as in the case of 16 urban parks in Iran (Bahriny \& Bell, 2020), that the level of management and maintenance, such as the maintenance of surfaces, has a positive relationship with the level of use of CBs; building occupancy, in turn, increases the need for maintenance (Boussabaine \& Kirkham, 2004). 
However, the AEC/FM industry usually "designs and builds infrastructure on the basis of first costs only, without explicit consideration of the maintenance and depreciation of the facility over its service life" (Mirza, 2006, p. 648), despite the maintenance period usually covering 95 percent of the project life-cycle (Bevilacqua \& Braglia, 2000) and their costs can account for a significant proportion of the entire life cycle costs (Boussabaine \& Kirkham, 2004). In particular, R\&M costs are difficult to cut due to the fact that the main goal of R\&M of buildings is to ensure that they and their equipment are at optimal operating levels (Au-Yong et al., 2017; ElSorady \& Rizk, 2020). From that, employers and structural managers are forced to reduce the time and cost and, at the same time, increase the useful life of structures and facilities (Liddle et al., 2020). In this regard, Shohet and Perelstein (2004) proposed a model for the allocation of a maintenance budget that can alternatively: 1) maximize the benefits while adhering to a fixed budget or, 2) minimize costs while putting the emphasis on the performance of the buildings. The first approach is suitable for organizations interested in reducing the costs of maintenance. The second approach is suitable for organizations wishing to achieve the highest performance possible.

However, the above methods can be used if accompanied with strong information management processes (Häkkinen \& Belloni, 2011; Munir et al., 2019; Shohet \& Nobili, 2016a, 2016b, 2017). As a consequence, building information modeling in structural management reduces the operational costs and risks and also improves the quality, energy efficiency, useful life, and safety of the build- ings (Kim et al., 2014; Sadeghi et al., 2019). In brief, these information management practices should be oriented to inform decision makers about the factors strongly influencing $\mathrm{R} \& \mathrm{M}$ costs. This has been demonstrated by Lavy and Bilbo (2009) who, by surveying 72 schools in Texas, found that having both administrative staff and students concerned with facility status and implementing visual inspections, using adequate tools, and recording facility condition images will help to build an information base, which has positive effects on building maintenance management.

In the field of commercial buildings (CBs), the core concept of the repair and maintenance $(\mathrm{R} \& \mathrm{M})$ consists of several steps, including: a) the primary identification of a $\mathrm{CB}$, which aims to classify the building by its type; $\mathrm{b}$ ) the secondary design/average service life of the building in years; and c) the preceding second step involves the following factors required for the evaluation of an existing CB:

1) Serviceability;

2) Ultimate limit states related to the structure, wear and damage and structural defects;

3) Energy parameters of building life cycle and their efficiency;

4) Costs related to building repair/reconstruction/ damage/new construction project;

5) Conditions and the situation in the Real Estate market, and the evaluation of benefits and payback terms;

6) Environmental improvements, reduction of $\mathrm{CO}_{2}$ emissions, etc.

The core concept is shown in Figure 1.

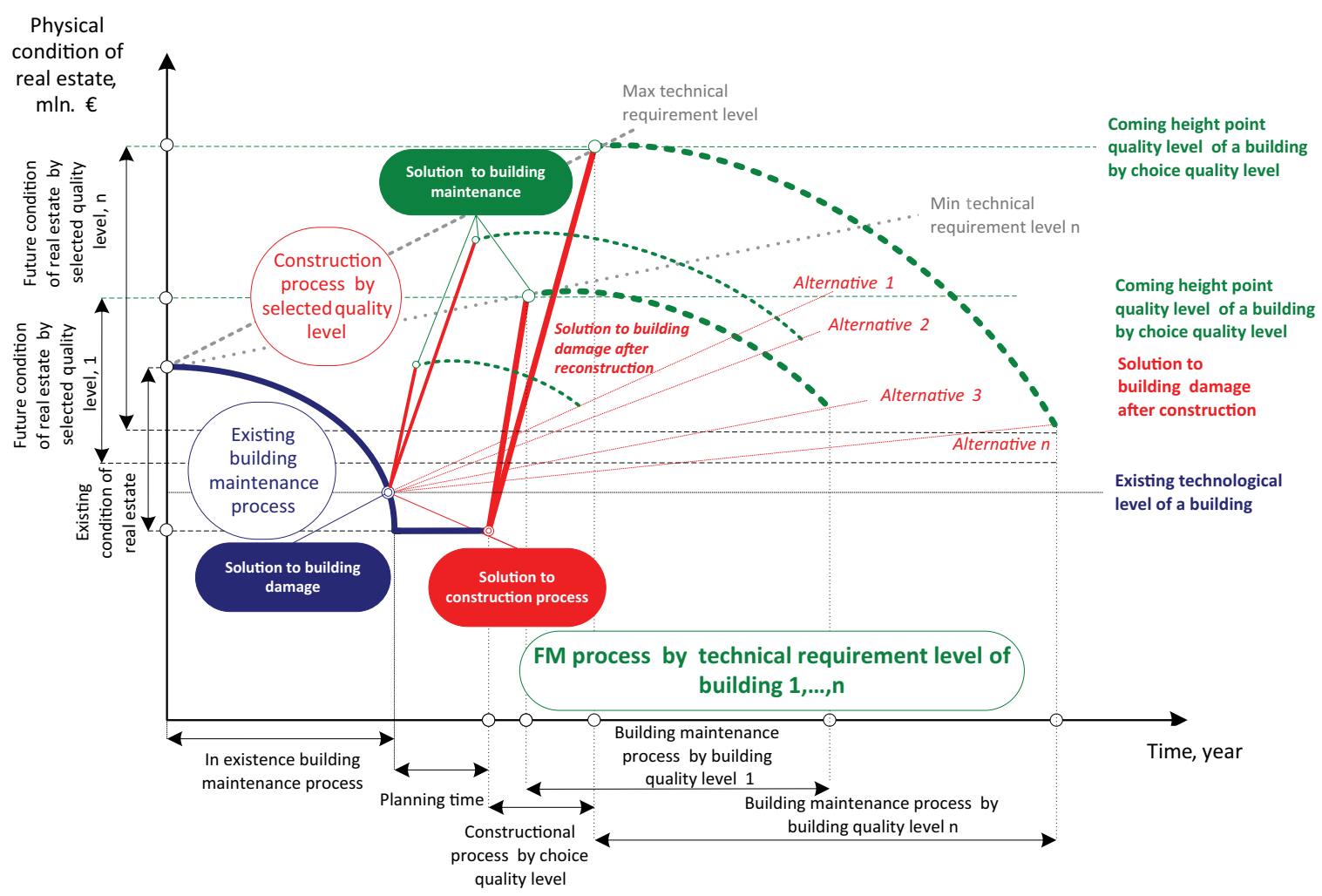

Figure 1. Core concept of repair and maintenance in CBs 
Every building and its environment are unique. The level of technical requirements for buildings depends on the purpose of the existing condition of a commercial building and its environment.

In particular, according to the established literature, the factors affecting the cost of maintenance include processes in AEC/FM (Lai, 2010; Lai et al., 2008); and a study by De Silva et al. (2012) illustrates that R\&M costs are reduced by $35 \%$, when these factors are minimized. It is possible to reduce these costs through the implementation of the right and appropriate R\&M method (De Silva et al., 2012), which leads to maximizing the utilization of the building.

Table 1 represents the different $R \& M$ methods adopted in the AEC/FM industry, as illustrated by Katebi and Almasian (2016) - of course, others have been produced (see Abu Dabous \& Alkass, 2008; Ghosh \& Roy, 2010), but this example seems the most complete and developed classification. An efficient R\&M method is aimed at improving the operating conditions of machinery, reducing the need for repair, and completely eliminating the causes of failure (Kizim, 2013). As identified by Katebi and Almasian (2016), the R\&M method is selected according to the type of the structure, the importance of the structure, properties of the used materials, and building occupancy. These strongly influence the R\&M decision; for example, Lavy and Shohet (2007) found, through a simulation study, that occupancy conditions affect the cumulative maintenance and replacement to a much greater extent than environmental conditions do; higher maintenance resources for high levels of occupancy and lower maintenance resources for low levels of occupancy. In particular, Shohet (2003) and Shohet et al. (2003) found, in the context of healthcare facilities, that the deterioration of some of the building systems under high occupancy conditions is accelerated and, in these cases, in-house provision (and manpower) offers opportunity for saving. In contrast, at standard or low occupancy levels, there is indeed an advantage as well as savings by employing external maintenance workers.
Due to $R \& M$ costs, choosing the proper method is important. However, Katebi and Almasian (2016) did not identify any of the reported R\&M methods as having superior performance over the others; their beneficial (or not) implementation depends, of course, on the context, such as the: 1) status of the existing building (in obsolescence terms), 2) date of construction of the building, 3) complaint about building performance, 4) customer application, 5) availability of budget, and 6) hygiene and safety requirements (Ali, 2009). From that, the identification of criteria on which to evaluate, periodically, their suitability (according to the context) is even more important than the R\&M method itself. These criteria are the subject of the following sub-section.

\subsection{Criteria for selecting appropriate repair and maintenance methods}

$\mathrm{R} \& \mathrm{M}$ of a building is unavoidable due to its continuous use, degradation of its components and problems caused by environmental factors. Yet, in developing countries, building and services' R\&M face even greater challenges due to lack of a budget and the side effects of the project (Thaheem \& De Marco, 2014; Wall, 1993).

As identified by Ruparathna et al. (2018), to reduce these challenges, an active management scheme with an approach to manage risks should be created; this would also allow correct identification of the criteria on which R\&M methods should be evaluated. Indeed, as already advanced, a fair assessment of R\&M methods is the main challenge in CBs, mainly because it is considered as a complex multiple-criteria decision-making (MCDM) problem (Shafiee, 2015). In this vein, Lee and Kim (2007), in assisting the Korean government in prioritizing routine maintenance, repair, rehabilitation, and replacement activities to optimize the given constrained budgets, suggested a genetic algorithm by which the selection of R\&M activities can be modelled as a multi-objective combinatorial optimization problem. Accordingly, Yousefli et al. (2020) proposed and simulated a multi-agent facility management

Table 1. Types of various maintenance strategies

\begin{tabular}{|l|l|}
\hline \multicolumn{1}{|c|}{ Strategy } & \multicolumn{1}{|c|}{ Description } \\
\hline $\begin{array}{l}\text { Reactive/emergency } \\
\text { maintenance }\end{array}$ & $\begin{array}{l}\text { Repair of the equipment is done after the first incident and there is no prior preparation; the } \\
\text { acquired experiences are not recorded }\end{array}$ \\
\hline $\begin{array}{l}\text { Repair of disablement based } \\
\text { on failure }\end{array}$ & $\begin{array}{l}\text { Repair actions are taken after failures. Notwithstanding, previous preparations for defect causes, } \\
\text { the corrective action required, repair instructions, tools, parts, and other required requirements } \\
\text { have been done }\end{array}$ \\
\hline Corrective repairs & $\begin{array}{l}\text { After witnessing the signs of a malfunction in equipment, there is a special plan to fix the } \\
\text { problem and to restore the original state of the equipment }\end{array}$ \\
\hline Preventive maintenance & $\begin{array}{l}\text { A scheduled timetable is prepared and the state of the building and its equipment is checked at } \\
\text { specific time periods }\end{array}$ \\
\hline $\begin{array}{l}\text { Maintenance based on the } \\
\text { situation }\end{array}$ & $\begin{array}{l}\text { In certain time periods, a number of equipment parameters in terms of vibration, pressure, and } \\
\text { temperature are measured. According to the implemented measurements, it is then decided } \\
\text { whether to repair or replace the parts and equipment }\end{array}$ \\
\hline $\begin{array}{l}\text { Effective maintenance and } \\
\text { pre-action }\end{array}$ & $\begin{array}{l}\text { Improving the operating conditions of machinery, reducing the need for repair, and completely } \\
\text { eliminating the causes of failure are the priorities }\end{array}$ \\
\hline
\end{tabular}


system (MAFMS), employing Unified Modeling Language (UML) diagrams that illustrate the specific agents of the system and how these agents interact with each other. The result of modeling workflows, as decentralized multi-agent processes, leads to reducing the response time to maintenance requests compared to the current maintenance system.

In terms of adopted criteria, Lam et al. (2010) reviewed the results of $110 \mathrm{R} \& \mathrm{M}$ management practices in contracting companies in Hong Kong and concluded that their success criteria mainly included time, cost, quality, performance, safety, and environmentally friendliness. Parida and Chattopadhyay (2007) developed a multi-criteria hierarchical framework for maintenance performance measurement (MPM) and grouped maintenance performance indicators under seven criteria: 1) indexes related to equipment: access, performance level, quality, and number of short and long stops, 2) indexes related to maintenance work: quality of work for maintenance, scheduled maintenance work, and illegal maintenance tasks, 3) indexes related to costs: maintenance cost and return on investment of maintenance, 4) indexes related to impact on customer satisfaction: number of quality complaints, low quality return, customer satisfaction, customer retention, and number of new customers, 5) indexes related to learning and development: number of new ideas, skills and development of merit, 6) indexes related to hygiene, safety, security and environment: health indexes, security, safety and environment, number of accidents, number of legal cases, number of cases of compensation, number of complaints about safety of hygiene, and health of the environment, and 7) indexes related to employee satisfaction: morale, personnel absenteeism, personnel complaints, and personnel travel rates. Apart from Lam et al. (2010), other scholars tried to identify the criteria to select R\&M methods; among them it is worth remembering the study of Pourjavad et al. (2013). These scholars, in particular, developed an analytic network process (ANP) method and the technique for order preference by similarity to an ideal solution (TOPSIS) to select a suitable R\&M strategy. In particular, they proposed the following steps: first, identify the prioritized criteria using the ANP method. In their case, they are: reliability, availability, maintainability, and cost employing. Then, pair-comparing R\&M strategies related to criteria, a table of importance of criteria is drawn up. Considering the table and weights of criteria that are evaluated by the ANP method, a decision-making matrix is formed. Finally, by employing the TOPSIS method, $\mathrm{R} \& \mathrm{M}$ strategies are ranked.

For buildings that are located in places where economies are influenced by constrained resources, Shohet (2003), instead, proposes that Condition-Based Maintenance $(\mathrm{CBM})$ is a common solution for the maintenance of large complex facilities. In particular, he advances two rating scales for the evaluation of a building's condition and forecast R\&M: one for the individual components, and a second for the entire building. The first scale combines criteria regarding the physical state, performance, fitness for use, and preventive maintenance of various building components. The second scale, instead, is a 100-point scale that covers 10 of the building's main systems. Following this, Shohet and Nobili (2016a, 2017), through their analysis of 13 courthouses and 42 community clinics located in Haayin (Israel), established a performance-based contract for the maintenance of public facilities consisting of: (1) a performance model based on the KPIs, (2) a procurement model, and (3) a contracting model. They found an increase of $20-40 \%$ in the performance-cost effectiveness of maintenance through the application of their proposed model (see also Shohet and Straub, 2013 for another application in the Netherlands and Israel), whose key parameters are: the creation of a clearly defined procurement model, assimilation of the performance model for both the owner (public agency) and the contractor in the contract, and performance control of the facilities. This framework, mainly based on a condition-dependent approach to maintenance and allowing the control desired maintenance performance levels and costs (Straub, 2002), can, moreover, lead to greater results if accompanied with the use of an Enterprise Resource Planning system (Shohet \& Nobili, 2016b). However, to strengthen the reported framework by Shohet and Straub (2013), a more comprehensive list of KPIs for performance evaluation of CBs is needed and a well-developed list is provided by Lai and Man (2017). In particular, these scholars, even if not offering a prioritization, produced a list of 71 items classified into five categories: (1) physical, (2) financial, (3) task and equipment related, (4) environmental, and (5) health, safety and legal.

The above-identified criteria, plus others emerging from the literature (reported in this theoretical background), for selecting R\&M methods are studied in this research to obtain insights into their applications in CBs; see Table 2. In the case of benchmarking legal issues, it should be clarified that the objective is to determine the type of contracts made at the time of AEC processes, which affects the choice of the R\&M method. Indeed, since maintenance costs due to the obligation to comply with legal issues may be affected, the legal issues' variable was grouped under Cost of Maintenance (CM) (see Christudason et al., 2010). This issue was also noted by Lai (2010) and Lai et al. (2004, 2006, 2009) who demonstrated the effect of legal disputes regarding conditions of R\&M contracts, i.e., stipulating the legal framework and specifications.

Recognizing these criteria helps managers to make better decisions to increase quality and reduce the issues of maintenance.

From the review by Shafiee (2015) on R\&M methods, and as reported in Table 2, it emerges that there are always a variety of criteria to be taken into account for selecting the most suitable R\&M method, "Some of these criteria are quantitative and measurable (such as hardware/software and training costs, equipment reliability/availability), 
Table 2. The evaluation criteria for the selection of R\&M methods for commercial buildings (CBs)

\begin{tabular}{|c|c|c|}
\hline No. & Criteria & Source \\
\hline 1 & Human resources & Ali (2009) \\
\hline 2 & Flexibility and technical capability & Lai et al. (2008) \\
\hline 3 & Facilities and technology & Motawa and Almarshad (2013) \\
\hline 4 & Risks & Ali (2009) \\
\hline 5 & Cost of maintenance & Lam et al. (2010); Ali (2009) \\
\hline 6 & Satisfaction of employees and consumers & Parida and Chattopadhyay (2007); Ali (2009) \\
\hline 7 & Having the necessary equipment & Parida and Chattopadhyay (2007) \\
\hline 8 & Saving energy consumption & Lai et al. (2008); Kim et al. (2014) \\
\hline 9 & $\begin{array}{l}\text { Structural and installation conditions of building (age, mechanical, } \\
\text { electrical, plumbing installations, and building structure) }\end{array}$ & Ali (2009) \\
\hline 10 & Better efficiency (added value) & Flores-Colen and de Brito (2010) \\
\hline 11 & Decrease of reactive decision making & Lind and Muyingo (2012) \\
\hline 12 & Identifying vicious factors & Motawa and Almarshad (2013) \\
\hline 13 & Management and integration of information & Motawa and Almarshad (2013) \\
\hline 14 & Number of experts & López et al. (2013) \\
\hline 15 & Compatibility with environment & Lam et al. (2010) \\
\hline 16 & Information note & López et al. (2013) \\
\hline 17 & Relations between managers and employees & Lee and Scott (2009) \\
\hline 18 & Facilities management & Zawawi and Kamaruzzaman (2009) \\
\hline 19 & Risk identification & Lind and Muyingo (2012) \\
\hline
\end{tabular}

and some others are qualitative and difficult to measure (such as safety, flexibility, acceptance by labours, product quality)" (Shafiee 2015, p. 384). Considering all of them, Shafiee (2015) grouped quantitative and qualitative criteria into: 1) economic (e.g., hardware cost, customer satisfaction, etc.), 2) technical (e.g., lead time, flexibility, etc.), 3) social (e.g., labor wage level, stakeholder participation, etc.), and 4) environmental (e.g., energy consumption, environmental protection, etc.). It is worth noticing that these four categories are strongly aligned with those in the recent review by Hauashdh et al. (2020) on the factors affecting building maintenance practices in Malaysia; in particular, these scholars classified criteria influencing R\&M in the following categories: 1) Management (i.e., strength of top administration, stakeholders' collaboration, preventive maintenance approach, quality of maintenance, strategic management plan), 2) Technical (i.e., design, Information and Communications Technology, techniques and tools to detect building defects), 3) Human Resources (i.e., expert building maintenance professionals, institutional training), and 4) Financial (i.e., budget allocation).

In this regard, Besiktepe et al. (2020) and Chua et al. (2014), in Colorado and Malaysia respectively, tried prioritizing criteria of procurement selection for building maintenance projects; results of the first study have shown "Health and Safety" was the main criterion for selection, while, for the second study, the main criterion was the "Price Competition" among potential suppliers. However, the above-cited studies did not consider some important criteria reported in Table 2, such as "Human
Resources" and "Flexibility and Technical Capability", leaving their analysis incomplete. Moreover, none of the produced studies trying to prioritize the R\&M method considered the Iranian context (Amani et al., 2012, 2013; Motamed \& Majrouhi, 2018), which is featured by highly constrained and unequally distributed resources (Ledford \& Lynch, 2019). In this regard, as demonstrated by Vanier et al. (2006) in their study aimed at comparing different prioritization techniques, the R\&M method to use highly depends on the assigned weight of factors made by evaluators, which vary by culture and organizational need.

\section{Research methodology}

This research aims to identify and rank the main criteria for selecting appropriate R\&M methods for Commercial Buildings (CBs). Similarly to Sarvari et al. (2020), to achieve the aim of the research, this study can be divided into three steps (Figure 2).

The first and second steps were the identification of the most important criteria that act as critical indicators for selection of R\&M methods for CBs. For this purpose, the existing desktop literature was reviewed, and 20 structured interviews were conducted with employees of the R\&M department and executive managers of the Iranian CB industry. The selected sample, which emerged from the row "Organization type", is formed by people from different organizations (i.e., 20). This ensured that the interviewed people are not an expression of the perception of one organization, but of many voices within the industry. 


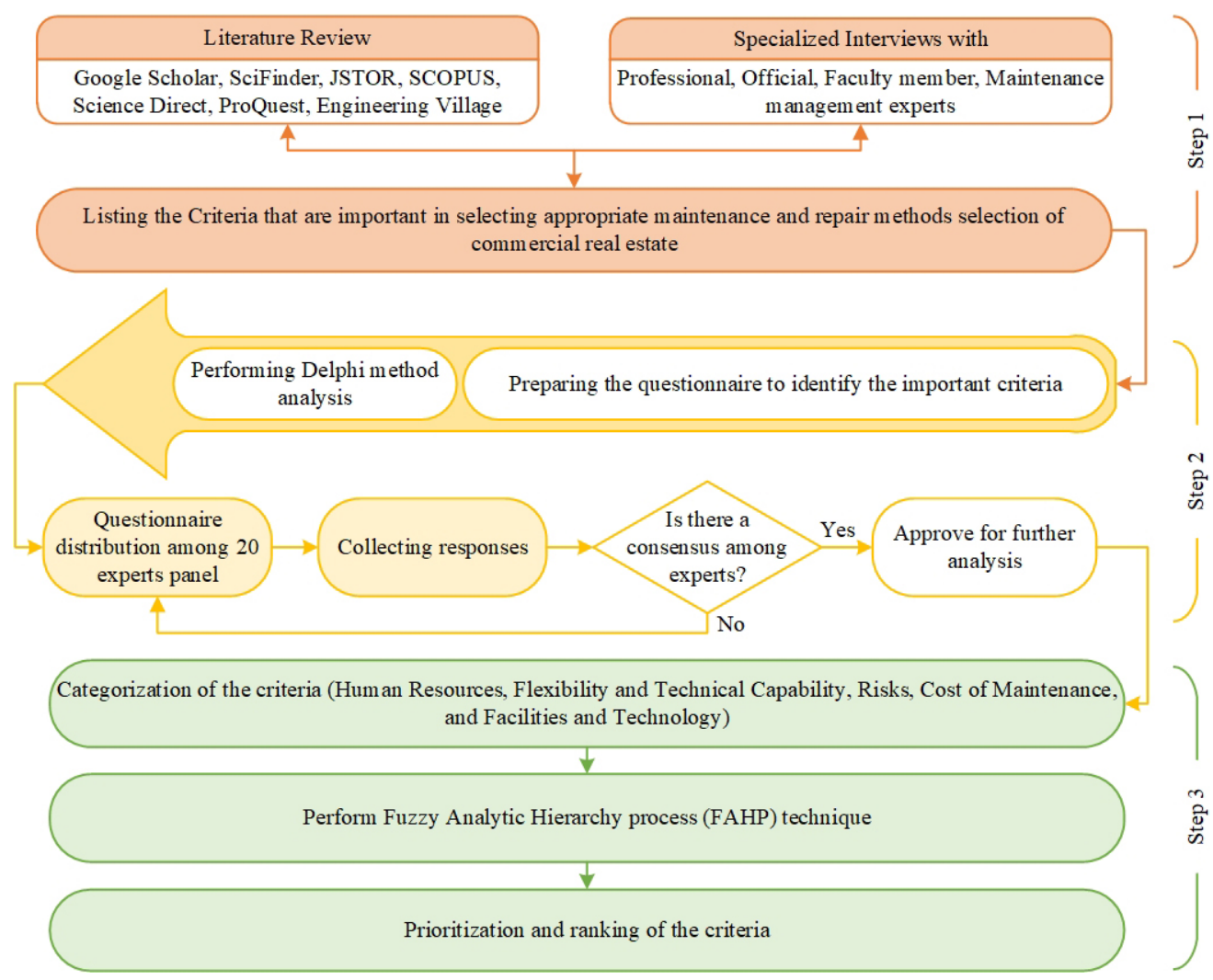

Figure 2. Developed research model for solving problems in this study

Table 3. Sample data description

\begin{tabular}{|l|c|c|}
\hline \multicolumn{1}{|c|}{ Socio-demographic feature } & Category & Frequency (\%) \\
\hline Educational level & Bachelor's degree & $9(45.0)$ \\
\cline { 2 - 3 } & Master's degree & $8(40.0)$ \\
\cline { 2 - 3 } & Ph.D. degree & $3(15.0)$ \\
\cline { 2 - 3 } & Less than 2 years & $2(10.0)$ \\
\cline { 2 - 3 } & 2 to 6 years & $6(30.0)$ \\
\cline { 2 - 3 } & 6 to 10 years & $4(20.0)$ \\
\hline Area of expertise & More than 10 years & $8(40.0)$ \\
\cline { 2 - 3 } & Civil engineering & $7(35.0)$ \\
\cline { 2 - 3 } & Mechanical engineering & $5(25.0)$ \\
\cline { 2 - 3 } & Electrical engineering & $3(15.0)$ \\
\cline { 2 - 3 } & Industrial engineering & $3(15.0)$ \\
\hline Age & Architecture & $2(10.0)$ \\
\cline { 2 - 3 } & $22-26$ years & $5(25.0)$ \\
\hline Organization type & $26-30$ years & $5(25.0)$ \\
\cline { 2 - 3 } & More than 30 years & $10(50.0)$ \\
\cline { 2 - 3 } & Architecture & $3(15.0)$ \\
\cline { 2 - 3 } & Engineering & $6(30.0)$ \\
\cline { 2 - 3 } & Construction & $3(15.0)$ \\
\hline
\end{tabular}


The characteristics of the selected population including academic degree, work experience, area of expertise, and age of the participants are listed in Table 3 . The most important criteria that emerged from the interviews were identified according to a mixed thematic analysis (Braun \& Clarke, 2006). In the second step, a questionnaire was prepared using the Saaty (1972) model and Saaty's ninepoint scale with the experts to determine the importance of each of the identified criteria. The FAHP technique was performed for the categorized indicators, which were prioritized and ranked based on the results of the analysis.

\subsection{Delphi survey method}

The use of specialized knowledge and views in collecting data to make decisions about problems with a qualitative nature is very effective (Sarvari et al., 2020). Hence, in this survey, following the previous studies and identifying the criteria for interviews, the Delphi technique was used to consensually identify and categorize the criteria (Hsu \& Sandford, 2007; Khosravi et al., 2020; Sarvari et al., 2019). The Delphi technique was used to determine the importance of criteria and to screen key criteria before applying a multi-criteria decision-making method, which has been successfully implemented in similar studies concerning the classification of strategies within the R\&M field (e.g., Ghazali et al., 2019; Hon et al., 2011, 2012). The Delphi technique is a structured process for collecting information to make decisions on qualitative issues (Chan \& Chan, 2012; Khoshfetrat et al., 2020; Olawumi \& Chan, 2018). The main purpose of the Delphi technique is to obtain the most reliable set of expert opinions through a series of structured questionnaires with controlled feedback. There are no strong and explicit rules on how to select and recruit experts, referred to as respondents of the Delphi questionnaires. However, it is worth mentioning that the quality of experts is more important than the quantity, which is usually less than 50 , and is often from 15 to 20 (Sarvari et al., 2020). The number of experts depends on factors including sample homogeneity, Delphi goal, difficulty range, quality of decision, ability of the research team, internal and external validity, time of data collection, available resources, and the scope of the problem (Chan \& Chan, 2012). The Delphi method has been used in previous similar contributions. For example, Chan and Chan (2012) applied the Delphi method to identify a performance measurement index for target cost contracts in construction. Yet, Sarvari et al. (2019) used the Delphi method to identify the risk identification approaches in public-private partnership (PPP) projects (see also Tamošaitienè et al., 2021). The Delphi panel of this study included 20 employees of the maintenance department and executive managers of Isfahan's CBs; they were chosen by convenience sampling and directly contacted by the researchers living in Iran. By agreeing on a group of experts through this process, researchers can identify and prioritize issues and develop a framework for identifying them.
In the first round of the Delphi study, a questionnaire including 9 criteria was distributed among the panel members who were asked to express their opinion on their approval or rejection; the criteria were: 1) Satisfaction of employees and consumers; 2) Number of experts; 3) Structure condition; 4) Identification of vicious factors; 5) Decrease of reaction decision making; 6) Environmentally friendly; 7) Saving energy consumption; 8) Management and integration of information; and 9) The presence of necessary equipment. In addition, panel members were asked to suggest other criteria that did not appear in the questionnaire. This is in line with the mixed thematic analysis approach. In particular, the mixed thematic analysis is based on both deductive analysis (by which communication messages are thematized according to an initial codebook; in this case, derived from the desktop review of the literature) and inductive analysis (by which new themes are free to emerge). Each author (of this paper) analyzed the transcripts individually and the inter-rater reliability between them was high (Cronbach's Alpha = 0.81 ); however, when disagreeing, together they delved deeper into the analysis in order to deliver a shared vision of the sentence meaning and related theme. By gathering and reviewing the opinions of the panel members in the first round and aggregating their views, it became clear they approved all 9 items in the questionnaire. In addition, four additional criteria were added to the original list of criteria: legal issues, organizational culture, increase of reliability, and ease of implementation. The questionnaire was modified by adding these 4 items and classifying the criteria according to groups: human resources, flexibility and technical capability, facilities and technology, risks, and cost of maintenance, as shown in Table 2. The updated questionnaire, consisting of 14 criteria in 5 different groups, was distributed among the panel members in a second round of the Delphi technique. In this round, also, participants were asked to comment on each criterion's approval or rejection, as well as their categories. Summing up the results of this step, it indicated that all 14 criteria presented in the questionnaire were confirmed by panel members. It was also suggested that the criterion of "increase the life of equipment" be added to group of cost of maintenance, and the criterion of "possibility to apply different techniques of repair and maintenance" be added to group of flexibility and technical capability, as new criteria. During this round, panel members also suggested that the criteria of number of expert forces and environmentally friendly be moved to the group of human resource and group of risks, respectively. Previously, these criteria were in the cost of maintenance and flexibility and technical capability groups. Due to new criteria being added and the proposed change in groupings, the questionnaire was redistributed in a third round of the Delphi technique. Finally, by gathering and reviewing the panel members' opinions, it became clear that all panel members agreed with the proposed criteria and their groupings. This led to a consensus among them. A total of 16 final items and their groupings were established. 


\subsection{Reliability and validity of the questionnaire}

From what has been discussed in the prior section, the final questionnaire was drawn up by reviewing the research literature and from experts' opinions collected via the three rounds of the Delphi technique. The validity of the questionnaire was tested through face and content validity. Face validity refers to the extent to which a test appears to measure what it is intended to measure; most people would agree that the test items appearing to measure what the test is intended to measure would have strong face validity (Johnson, 2013). Content validity, instead, exists in a questionnaire when the items pertain to what is being measured and when the items encapsulate what is relevant to the construct being measured (Preedy, 2010). For the content validity of the questionnaire, the Content Validity Ratio (CVR) and the Content Validity Index (CVI) were calculated. CVR is used in order to measure content validity based on experts' opinions. To calculate it, firstly the aim of the test was explained to the experts - who were met in person in 2019 - who were then asked to score each item (in 30 minutes) using the Likert scale between "necessary item", "useful but not necessary item" and "unnecessary item", of course with reference to R\&M activities for CBs. The CVR was calculated using Equation (1):

$$
C V R=\frac{\left[n-\frac{N}{2}\right]}{\left(\frac{N}{2}\right)},
$$

where: $N$ is the total number of experts and $n$ is the number of experts who have selected the "necessary item" option. The minimum acceptable CVR value for a total of 10 experts is equal to 0.62 (Pezshki et al., 2017). Items with CVR values lower than this threshold should be eliminated from the test due to lack of suitable content validity. Then, experts were asked to score each item regarding its Relevance, Simplicity, and Clarity using a 4-level Likert scale. The experts scored Relevance using 1 ("irrelevant"), 2 ("somewhat relevant"), 3 ("relevant"), and 4 ("fully relevant"). Simplicity was also scored using 1 ("not simple"), 2 ("somewhat simple"), 3 ("simple"), and 4 ("simple and relevant"), while Clarity was scored using 1 ("unclear"), 2 ("somewhat clear"), 3 ("clear"), and 4 ("clear and relevant"). The Content Validity Index then was calculated using Equation (2):

$$
C V I=\frac{\text { number of experts giving } 3 \text { and } 4 \text { scores }}{\text { total number of experts }} .
$$

The minimum acceptable threshold for CVI is 0.79 and items with scores below this threshold are eliminated (Pezshki et al., 2017; Fadavi-Ghaffari et al., 2017). In order to measure the face validity of the items, the item impact score test was used. In order to calculate item impact scores, firstly participants were asked to score the importance of each item in the questionnaire using a 5-level Likert scale from 1 ("not important at all"), 2 ("a little important"), 3 (“somewhat important"), 4 (“important"), and 5 ("very important").
The face validity value of items must not be below 1.5 and only items with impact scores higher that 1.5 are retained (Fadavi-Ghaffari et al., 2017). The results of face and content validity evaluations showed that all items have suitable face and content validity scores. Yet, the reliability of the items was investigated and items with low reliability were removed in order to improve the overall reliability of the test. Various methods are used to measure reliability. In this study, Cronbach's Alpha coefficient was calculated using SPSS software. The Cronbach's Alpha value must be higher than 0.7 (Taber, 2018). The Cronbach's Alpha value calculated in the current study was 0.916 , which indicates that all items have suitable reliability.

\subsection{Fuzzy Analytic Hierarchy Process (FAHP) technique}

Multiple criteria decision making (MCDM) has grown as a part of operations research, concerned with designing computational and mathematical tools for supporting the subjective evaluation of performance criteria by decision makers (Sarvari et al., 2019; Zavadskas et al., 2014).

In recent years several previous studies have employed MCDM tools such as Analytic Network Process (ANP), Analytic Hierarchy Process (AHP), Fuzzy Analytic Hierarchy Process (FAHP), and applications to solve problem areas such as determining the Criteria for selecting appropriate decisions. The Analytic hierarchy process (AHP) is an effective method that can solve a multiple criteria decision-making problem that can be applied to the R\&M problem maintenance to gain a scientific and objective view on maintenance scheduling (Al-Shammari \& Mili, 2019; Alani et al., 2002; Galar et al., 2011). Selection of a R\&M strategy for a particular machine or group of machines is a problem of decision making and it is always a challenging task for the maintenance Manager/Engineer. By using the decision-making tools like AHP, this problem can be solved. The use of the AHP method also facilitates calculating the weight of factors through which the decision maker can analyze the difference between actual condition and required condition. Present research work shows that the problem of selecting an optimum maintenance strategy for a machine can be overcome by using a decision-making tool (AHP) (Chandrahas et al., 2015).

When decision makers and/or experts are unsure of their response to a survey result, the AHP is unable to address this uncertainty. However, FAHP can take this into consideration when performing pairwise comparisons. The FAHP approach has been used by previous researches. Applying fuzzy sets is more consistent with vague explanations and human linguistics, and using fuzzy numbers seems to be a proper way to make decisions (Sarvari et al., 2021). Dabiri et al. (2020) indicated that using the FAHP method for group decisions could resolve the fuzziness of frequent misunderstanding of specialist opinions. Therefore, this method is an appropriate way to evaluate the importance of the parameters affecting a phenomenon or a concept on a more flexible scale. In this regard, Sayed 
et al. (2019) used the fuzzy AHP for prioritizing lean construction barriers in Qatari civil companies. Sarvari et al. (2020) applied FAHP for prioritizing the barriers of privatization of water and wastewater infrastructure projects. In this study, FAHP was used also to prioritize selecting the methods of R\&M of CBs. This approach is based on pairwise comparisons based on the experts' points of view. Similarly to Suganthi (2018), the six implementation steps of the FAHP method in this study are reported as follows:

1 - When multiple respondents reply to paired comparisons, the geometric mean method is used to integrate them to obtain an integrated paired comparison matrix. The integration of fuzzy matrices is such that the first data gathers all the comparisons with each other geometric mean, the second data with each other, and the third data with the geometric mean. As a result, a hierarchical tree (identifying the purpose, criteria and sub-criteria) is drawn up.

2 - Then, the fuzzy numbers of each row are added together. In this regard, a Pairwise Comparison Matrix Formation $(\tilde{X})$ is implemented: Each pairwise formation of matrix comparisons $\tilde{X}$ is displayed as $\tilde{x}_{i j}$. The Pairwise comparison matrix is presented in Table 4 .

Table 4. Pairwise comparison matrix

\begin{tabular}{|c|c|c|c|}
\hline$C_{n}$ & $\ldots$ & $\mathrm{C} 1$ & \\
\hline & & $(1,1,1)$ & $\mathrm{C} 1$ \\
\hline$\ldots$ & $\ldots$ & $\ldots$ & $\ldots$ \\
\hline$(1,1,1)$ & & & $C_{n}$ \\
\hline
\end{tabular}

3 - Consolidation of experts' views: In order to consolidate the experts' views, the geometric mean of each of the three triangular fuzzy numbers is used.

$$
\tilde{F}_{A G R}=(\Pi(l), \Pi(m), \Pi(u)) .
$$

4 - Calculate the sum of the elements in each row.

$$
\tilde{S}_{i}=\sum_{j=1}^{n} \tilde{x}_{i j} \cdot
$$

5 - Normalize the sum of the elements in each row: To do this, Saaty's (1972) special vector technique is used. The fuzzy sum is the sum of column elements.

$$
\sum_{i=1}^{n} \tilde{S}_{i}
$$

And is also displayed as follows

$$
\sum_{i=1}^{n} \sum_{j=1}^{n} M_{g}^{j}
$$

To normalize the sum of the preferences of each criterion, the sum of the values of that criterion must be divided by the sum of all the preferences (column elements).

$$
\tilde{M}_{i}=\tilde{S}_{i} \otimes\left[\sum_{i=1}^{n} \tilde{S}_{i}\right]^{-1} .
$$

Because the values are fuzzy, the fuzzy sum of each row is multiplied by the inverse of the sum. The inverse of the sum must be calculated.

$$
\begin{aligned}
& M_{1}{ }^{-1}=\left(1 / u_{1}, 1 / m_{1}, 1 / l_{1}\right) ; \\
& \left(\sum_{i=1}^{n} \sum_{j=1}^{n} M_{g}^{j}\right)^{-1} ; \\
& S_{k}=\sum_{i=1}^{n} M \cdot\left(\sum_{i=1}^{n} \sum_{j=1}^{n} M_{g}^{j}\right)^{-1} .
\end{aligned}
$$

These calculations are summarized in Table 5.

Table 5. Summary of fuzzy calculations

\begin{tabular}{|c|c|c|c|c|}
\hline Fuzzy set & $C_{n}$ & $\ldots$ & $\mathrm{C} 1$ & \\
\hline$\tilde{S}_{1}=\sum_{j=1}^{n} \tilde{a}_{1 j}$ & & & $(1,1,1)$ & $\mathrm{C} 1$ \\
\hline$\ldots$ & $\ldots$ & $\ldots$ & $\ldots$ & $\ldots$ \\
\hline$\tilde{S}_{n}=\sum_{j=1}^{n} \tilde{a}_{n j}$ & & & & $C_{n}$ \\
\hline$\left[\sum_{i=1}^{n} \tilde{S}_{i}\right]$ & \multicolumn{5}{|l}{} & \\
\hline
\end{tabular}

6 - Defuzzification of the values and determining the final weights of the elements: To do this, the triangular fuzzy method is used (Chang, 1996). Consider two triangular numbers, $M_{1}=\left(l_{1}, m_{1}, u_{1}\right)$ and $M_{2}=\left(l_{2}, m_{2}, u_{2}\right)$. The two basic concepts of the fuzzy hierarchical analysis process based on the development analysis method are as follows:

$$
\begin{aligned}
& V\left(M_{2} \geq M_{1}\right)=\operatorname{hgt}\left(M_{2} \geq M_{1}\right)=\mu_{F_{2}}(d) ; \\
& V\left(M_{2} \geq M_{1}\right)=\left\{\begin{array}{c}
1 \quad \text { if }\left(m_{2} \geq m_{1}\right) \\
\frac{l_{1}-u_{2}}{\left(m_{2}-u_{2}\right)-\left(m_{1}-l_{1}\right)} \text { else }
\end{array}\right.
\end{aligned}
$$

where: $d$ is the coordinate of the highest point in the interface and collision of the two membership functions $\mu_{M_{2}}$ and $\mu_{M_{1}}$. As shown in Figure 3, this point is also visible.

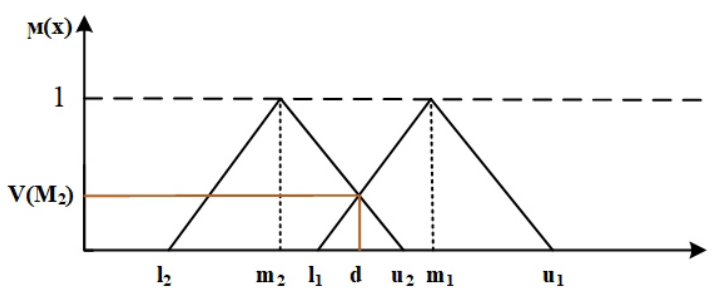

Figure 3. The distance of two triangular fuzzy numbers (Sarvari et al., 2021) 
To compare $M_{1}$ and $M_{2}$, it is necessary to calculate both $V\left(M_{2} \geq M_{1}\right)$ and $V\left(M_{1} \geq M_{2}\right)$. The degree of probability of a convex fuzzy number being greater than $k$ of another convex fuzzy number is calculated as follows:

$$
\begin{aligned}
& V\left(M \geq M_{1}, M_{2}, \ldots, M_{k}\right)= \\
& V\left[\left(M \geq M_{1}\right),\left(M \geq M_{2}\right), \ldots,\left(M \geq M_{K}\right)\right]= \\
& \min V\left(M \geq M_{i}\right) i=1,2, \ldots, k .
\end{aligned}
$$

The center of gravity method has been used. In this method, the following is done to de-fuzzy the triangular fuzzy numbers:

$$
\begin{aligned}
& F=(L, M, U) ; \\
& x_{m}^{1}=\frac{L+M+U}{3} ; \\
& x_{m}^{2}=\frac{L+2 M+U}{4} ; x_{m}^{3}=\frac{L+4 M+U}{6} ;
\end{aligned}
$$

$$
\text { Crisp number }=Z^{\star}=\max \left(x_{\max }^{1}, x_{\max }^{2}, x_{\max }^{3}\right) \text {. }
$$

The values of $x \_\max ^{\wedge} i$ are not much different and are always a number close to $M$. $M$ is the mean of the sum of the probable values of $\mathrm{m}$ from different triangular fuzzy numbers. However, the definite value of the largest $x^{i}$ is considered. Finally, the de-fuzzy value is for final analysis to determine the weight of the criteria. It should be noted that the calculated weights are non-fuzzy but should be normalized.

\section{Fuzzy Analytic Hierarchy Process (FAHP) technique}

\subsection{Identification and categorization of the evaluation criteria}

As shown in Table 6, a total of 16 individual selection criteria were identified as important indicators for selecting the methods of maintaining and repairing of CBs.

The sub-criteria were further grouped into five main categories: 1) Human Resources (HR): satisfaction of employees and consumers, organizational culture, and number of expert forces; 2) Flexibility and Technical Capability (FTC): ease of implementation, possibility to apply different techniques of repair and maintenance, and structural condition; 3) Risks (R): identification of malicious factors, decrease of reaction decision making, enhanced reliability, and environmentally friendly; 4) Cost of Maintenance (CM): saving energy consumption, increase the life of equipment, efficiency (value added), and legal issues; and 5) Facilities and Technology (FT): management and information integration, and the presence of necessary equipment.

\subsection{Prioritization of the main selection criteria}

The FAHP technique was used to determine the priority of the identified main criteria and the data analysis of the FAHP method was carried out in Excel software.

\begin{tabular}{|c|c|c|c|}
\hline & Main criterion & Sub-criteria & Source \\
\hline 1 & \multirow[t]{3}{*}{ Human resources (HR) } & Satisfaction of employees and consumers & Parida and Chattopadhyay (2007) \\
\hline 2 & & Organizational culture & Interview \\
\hline 3 & & Number of experts & López et al. (2013) \\
\hline 4 & \multirow{3}{*}{$\begin{array}{l}\text { Flexibility and technical } \\
\text { capability (FTC) }\end{array}$} & Ease of implementation & Interview \\
\hline 5 & & $\begin{array}{l}\text { Possibility to apply different techniques of repair and } \\
\text { maintenance }\end{array}$ & Interview \\
\hline 6 & & Structural condition & Ali (2009) \\
\hline 7 & \multirow[t]{4}{*}{ Risks (R) } & Identification of malicious factors & Motawa and Almarshad (2013) \\
\hline 8 & & Decrease of reaction decision making & Hon et al. (2011) \\
\hline 9 & & Enhanced reliability & Interview \\
\hline 10 & & Environmentally friendly & Lam et al. (2010) \\
\hline 11 & \multirow{4}{*}{$\begin{array}{l}\text { Cost of maintenance } \\
(\mathrm{CM})\end{array}$} & Saving energy consumption & Lai et al. (2008); Kim et al. (2014) \\
\hline 12 & & Increase the life of equipment & Interview \\
\hline 13 & & Efficiency (value added) & Interview \\
\hline 14 & & $\begin{array}{l}\text { Legal issues (i.e., maintenance costs arising from legal } \\
\text { issues) }\end{array}$ & $\begin{array}{l}\text { Lai (2010); Lai et al. }(2004,2006 \text {, } \\
\text { 2009) }\end{array}$ \\
\hline 15 & \multirow{2}{*}{$\begin{array}{l}\text { Facilities and technology } \\
\text { (FT) }\end{array}$} & Management and integration of information & Motawa and Almarshad (2013) \\
\hline 16 & & The presence of necessary equipment & Parida and Chattopadhyay (2007) \\
\hline
\end{tabular}
The paired matrix for the categories was obtained after comparing the pairs of categories based on the target, and determining their weight, based on the fuzzy geometric average of the expert's choice. The integrated fuzzy comparison matrix for the criteria is given in Table 7.

Table 6. The main evaluation criteria and its sub-criteria for selecting the repair and maintenance methods of CBs 
Table 7. The integrated fuzzy comparison matrix for the main selection criteria

\begin{tabular}{|l|l|l|l|l|l|l|l|l|l|l|l|l|l|l|l|l|}
\hline & \multicolumn{3}{|c|}{ HR } & \multicolumn{3}{c|}{ FTC } & \multicolumn{3}{c|}{ R } & \multicolumn{3}{c|}{ CM } & \multicolumn{2}{c|}{ FT } \\
\hline HR & 1.00 & 1.00 & 1.00 & 0.87 & 1.11 & 1.36 & 0.61 & 0.79 & 1.04 & 0.57 & 0.72 & 0.93 & 0.56 & 0.71 & 0.91 \\
\hline FTC & 0.73 & 0.90 & 1.16 & 1.00 & 1.00 & 1.00 & 1.26 & 1.47 & 1.67 & 0.88 & 1.11 & 1.34 & 0.98 & 1.18 & 1.34 \\
\hline R & 0.96 & 1.27 & 1.63 & 0.60 & 0.68 & 0.79 & 1.00 & 1.00 & 1.00 & 0.92 & 1.08 & 1.29 & 1.09 & 1.42 & 1.83 \\
\hline CM & 1.07 & 1.38 & 1.77 & 0.75 & 0.90 & 1.13 & 0.78 & 0.93 & 1.09 & 1.00 & 1.00 & 1.00 & 1.50 & 1.79 & 2.06 \\
\hline FT & 1.10 & 1.42 & 1.79 & 0.75 & 0.85 & 1.02 & 0.55 & 0.70 & 0.91 & 0.49 & 0.56 & 0.67 & 1.00 & 1.00 & 1.00 \\
\hline
\end{tabular}

Table 8. Fuzzy sum, fuzzy expansion, and degree of preference for the main selection criteria

\begin{tabular}{|l|l|l|l|l|l|l|l|l|c|c|}
\hline & \multicolumn{3}{|c|}{ Fuzzy sum of each row } & \multicolumn{3}{c|}{ Fuzzy compound expansion } & \multicolumn{4}{c|}{ Degree of preference of $S_{i}$ over $S_{k}$} \\
\hline HR & 3.604 & 4.326 & 5.249 & 0.117 & 0.167 & 0.238 & 0.609 & 0.675 & 0.530 & 0.936 \\
\hline FTC & 4.861 & 5.667 & 6.500 & 0.158 & 0.218 & 0.295 & 1.000 & 1.000 & 0.910 & 1.000 \\
\hline R & 4.570 & 5.447 & 6.540 & 0.149 & 0.210 & 0.297 & 1.000 & 0.943 & 0.861 & 1.000 \\
\hline CM & 5.095 & 5.998 & 7.047 & 0.166 & 0.231 & 0.320 & 1.000 & 1.000 & 1.000 & 1.000 \\
\hline FT & 3.878 & 4.526 & 5.392 & 0.126 & 0.174 & 0.245 & 1.000 & 0.664 & 0.731 & 0.583 \\
\hline
\end{tabular}

Table 9. Degree of preference and final weight for the main selection criteria

\begin{tabular}{|l|c|c|c|}
\hline Criteria & Degree of preference & Normalization of preferences & Rank \\
\hline HR & 0.530 & 0.1365 & 5 \\
\hline FTC & 0.910 & 0.2344 & 2 \\
\hline R & 0.861 & 0.2217 & 3 \\
\hline CM & 1.000 & 0.2575 & 1 \\
\hline FT & 0.583 & 0.1500 & 4 \\
\hline
\end{tabular}

In addition, the fuzzy sum of each row, the fuzzy compound expansion, and the degree of preference of $S_{i}$ over $S_{k}$ for the criteria is given in Table 8. Moreover, Table 9 shows the degree of preference for criteria and the normalization of preferences for the criteria. The results showed that CM (0.2575) and FTC (0.2344) greatly influence the selection of maintenance methods of CRE. R and FT scored 0.2217 and 0.1500 , respectively, while HR records the lowest weight at 0.1365 .

To calculate the consistency ratio (CR), the consistency index (CI) is divided by the random index (RI). If the result is lower than 0.1 , the matrix is consistent and usable for data evaluation. If both $\mathrm{CR}^{\mathrm{m}}$ (obtained consistency ratio based on the middle numbers of the triangular fuzzy matrix) and $\mathrm{CR}^{\mathrm{g}}$ (obtained consistency ratios based on the geometric mean of the upper and lower bounds of the triangular fuzzy matrix) indices are under 0.1 , then the fuzzy matrix is compatible; however, if both indices are higher than 0.1, the decision maker is asked to revise the prioritization (Deng, 1999; Thengane, 2019). For the criteria, both of these indices are less than $0.1\left(\mathrm{CR}^{\mathrm{m}}=0.0246\right.$, $\mathrm{CR}^{\mathrm{g}}=0.0681$ ), which are the allowable values.

The FAHP technique was used to determine the priority of sub-criteria within each category. The results and the weights related to the sub-criteria are shown in Table 10. Among the sub-criteria of HR, the Number of Expert Forces (NEHR) and the Satisfaction of Employees and Consumers (SEAC) had a higher score compared to Organizational Culture (OC). Meanwhile, for the FTC sub-criteria, the Structure Condition (SC), the Ease of Implementation (EI), and the Possibility to Apply Different Techniques of R\&M (PAVTRM) had the highest-tolowest weights. Under the R sub-criteria, Identification of Malicious Factors (CIMF), Decrease of Reaction Decision making (DRD), Enhancement of Reliability (ER), and Environmentally Friendly (CWE) had the highest-to-lowest weights. In addition, sub-criteria, such as the Increase the Life of Equipment (ILE), the Efficiency (value-added) (IEVA), Saving Energy Consumption (SEC), and Legal Issues (LI) had the highest-to-lowest weights among the sub-criteria of CM. Moreover, for the FT sub-criteria, the Presence of Necessary Equipment (PNE) has a higher score compared to the Management and Information Integration (MMI). In total, the results revealed that the Presence of Necessary Equipment (PNE) and Legal issues (LI) sub-criteria are the most important and the least important for R\&M methods for CRE, respectively. 
Table 10. Determination of the final priority of the main selection criteria and sub-criteria with the FAHP technique

\begin{tabular}{|c|c|c|c|c|c|c|c|c|}
\hline Criteria & $\mathrm{CR}^{\mathrm{m}}$ & $\mathrm{CR}^{\mathrm{g}}$ & Weight & Sub-criteria & Weight & $\begin{array}{c}\text { Rank within } \\
\text { category }\end{array}$ & Final weight & Overall rank \\
\hline \multirow[t]{3}{*}{ HR } & \multirow[t]{3}{*}{0.0030} & \multirow[t]{3}{*}{0.0055} & \multirow[t]{3}{*}{0.1365} & SEAC & 0.286 & 2 & 0.039 & 8 \\
\hline & & & & $\mathrm{OC}$ & 0.283 & 3 & 0.039 & 9 \\
\hline & & & & NEHR & 0.431 & 1 & 0.059 & 3 \\
\hline \multirow[t]{3}{*}{ FTC } & \multirow[t]{3}{*}{0.0027} & \multirow[t]{3}{*}{0.0049} & \multirow[t]{3}{*}{0.2344} & EI & 0.249 & 2 & 0.058 & 11 \\
\hline & & & & PAVTRM & 0.206 & 3 & 0.048 & 14 \\
\hline & & & & SC & 0.545 & 1 & 0.128 & 2 \\
\hline \multirow[t]{4}{*}{$\mathrm{R}$} & \multirow[t]{4}{*}{0.0030} & \multirow[t]{4}{*}{0.0072} & \multirow[t]{4}{*}{0.2217} & CIMF & 0.292 & 1 & 0.065 & 7 \\
\hline & & & & DRD & 0.265 & 2 & 0.059 & 10 \\
\hline & & & & CWE & 0.218 & 4 & 0.048 & 13 \\
\hline & & & & ER & 0.225 & 3 & 0.050 & 12 \\
\hline \multirow[t]{4}{*}{$\mathrm{CM}$} & \multirow[t]{4}{*}{0.0048} & \multirow[t]{4}{*}{0.0139} & \multirow[t]{4}{*}{0.2575} & SEC & 0.197 & 3 & 0.051 & 15 \\
\hline & & & & ILE & 0.442 & 1 & 0.114 & 4 \\
\hline & & & & IEVA & 0.340 & 2 & 0.088 & 6 \\
\hline & & & & LI & 0.020 & 4 & 0.005 & 16 \\
\hline \multirow[t]{2}{*}{ FT } & \multirow[t]{2}{*}{-} & \multirow[t]{2}{*}{ - } & \multirow[t]{2}{*}{0.1500} & PNE & 0.576 & 1 & 0.086 & 1 \\
\hline & & & & MMI & 0.424 & 2 & 0.064 & 5 \\
\hline
\end{tabular}

\section{Discussion of analytical results}

The R\&M period is a major part of the lifespan of a building; it usually covers 95 percent of the project life-cycle (Bevilacqua \& Braglia, 2000). This indicates that special attention should be paid to this tricky situation in which the need to cut costs should be handled with the consideration that equipment should always be at their optimal operating levels (Au-Yong et al., 2019; ElSorady \& Rizk, 2020). In order to identify the best R\&M methods that can satisfy these intertwined needs, this research has tried classifying and prioritizing the criteria for their assessment for Commercial Buildings. Commercial Building (CB) centers are among the structures where $R \& M$ is of utmost importance since they draw vast numbers of visitor traffic due to the extensive shopping opportunities they provide. Identifying proper R\&M methods and evaluation criteria for applying these methods to such structures makes it possible to save a significant amount of cost and time. This is even more important in developing countries, the context of this research, where building and services R\&M faces even greater challenges due to lack of resources (Motamed \& Majrouhi, 2018; Thaheem \& De Marco, 2014; Wall, 1993).

In order to fill this gap, a list of criteria affecting the proper R\&M method selection for CRE was identified. Also, a Delphi questionnaire, based on the identified criteria, was developed and distributed among the invited experts. In this step, a total of 16 criteria were identified and categorized into five different groups and the FAHP approach was used to prioritize the identified criteria. Pairwise comparison questionnaires were distributed among experts and results showed that the Cost of Maintenance (CM), Flexibility and Technical Capability (FTC),
Risks (R), Facilities and Technology (FT) and Human Resources (HR) criteria are in the first to fifth ranks, respectively. Also, the results showed that the Presence of Necessary Equipment (PNE) and Legal Issues (LI) sub-criteria are the most important and the least important for maintenance and repair methods of CBs in Iran, respectively.

The order of criteria for selecting R\&M methods is the following: CM, FTC, R, FT, and HR. This ranking is, partly, in line with was has been found by Lam et al. (2010) who reviewed the results of $110 \mathrm{R} \& \mathrm{M}$ management practices in contracting companies in Hong Kong; the authors identified time and cost as pivotal factors to consider in R\&M evaluations - in spite of not formalizing a hierarchical analysis.

Yet, results of the proposed analysis, in terms of classification, are almost aligned with the categorization proposed by the review of Shafiee (2015). In fact, while this scholar proposed to divide criteria for the assessment of R\&M methods into: 1) economic (e.g., hardware cost, customer satisfaction, etc.), 2) technical (e.g., lead time, flexibility, etc.), 3) social (e.g., labor wage level, stakeholder participation, etc.), and 4) environmental (e.g., energy consumption, environmental protection, etc.), this research has proposed dividing them into: 1) Cost of Maintenance (CM), 2) Flexibility and Technical Capability (FTC), 3) Risks (R), 4) Facilities and Technology (FT), and 5) Human Resources (HR). From the comparison of the above two classifications, a correspondence emerges between the two economic and technical terms, categories 1) and 2) the environmental topic of Shafiee (2015) resides within the $\mathrm{R}$ category, while the social one can be considered as included in the HR variable. However, 
if looking more closely at both these two exceptions, the new - with respect to Shafiee (2015) - FT category, and the sub-criteria included in all the 5 proposed categories of this research, it emerges that this categorization looks more at the internal factors of the organization that would implement R\&M activities rather than Shafiee (2015). This is not a complete drawback; indeed, while the proposed categorization seems to be comprehensive of all internal factors but not external ones, the categorization of Shafiee (2015) seems to include part of the internal factors of the organization and part of the external ones, without being comprehensive of either. The advantage of this research is in having employed a mixed qualitative-quantitative analysis; results of the interviews with experts have been quantified and a prioritization model has been built in accordance with the results. In doing that, this research has precisely answered the call of Shafiee (2015) who highlighted how few attempts have been made to combine qualitative approaches (survey and interviewing methodology) with quantitative techniques (mathematical modelling) in order to solve the R\&M methods' selection. In this vein, stemming from the fact the selection of an appropriate maintenance strategy is a group decision-making problem and cannot be performed on an individual basis, attention has been paid, through the implementation of the Delphi study, to the diversity of information given by maintenance experts, which was another gap identified by Shafiee (2015) but has been tackled by this research.

From the reported results, some differences emerge from the comparison in prioritizing the criteria among developed countries and developing countries. For example, results of this research are in contrast with those of Besiktepe et al. (2020), who found that criteria for selecting R\&M methods, such as "Health and Safety", "Code Compliance", and "Condition", have higher importance in a developed country; while in this study, it has been found that $\mathrm{CM}$ is the most important criterion. From the study of Sodangi et al. (2014), the most important criterion, in Malaysia, was maintenance staff training and expertise equal to the HR category of this research; however, this result is in contrast with the one by Chua et al. (2014) that identified "Price Competition" as the main important criterion for the procurement of R\&M decisions in Malaysia. The same has been found, again in Malaysia, by Ali (2009) who found, through a survey administered to 200 selected buildings' managers, that the main factors usually considered by the building managers in allocating maintenance costs are the availability of funding, the client's preference, and economic situation. Yet, with regard to the maintenance of wastewater systems in Iran, Amani et al. (2013), despite not considering different criteria, identified the cost of maintenance as the suggested method for R\&M.

So, stemming from the emerging differences with similar studies, it clearly appears that there is not strong homogeneity of criteria among developed and developing countries, while there seems to be a certain degree of homogeneity when looking at the studies conducted in Iran and developing countries. In practice, for decision makers in developing countries, but, especially in Iran where results seem to be more convergent (see Amani et al., 2013), the cost of maintenance is the main method for selecting how to repair and maintain a building.

In order to better convey the explained result, the following example is provided. A 20-year-old CB in Tehran (Iran) needs to be partly restructured and the management has to make the decision between: a) repair the existing ceramic tiling, or b) replacing it with a natural stone cladding. According to the results of this work, the management will look for data concerning all 5 identified main criteria (HR, FTC, R, CM, and FT) and compare the two methods correspondingly. However, within this comparison, what is more relevant - to the eyes of decision makers - is the CM category (formed by the following sub-criteria: saving energy consumption, increase the life of equipment, efficiency, and legal issues). From that, decision makers weight these sub-criteria over the two methods (Table 11).

Within the proposed example, to facilitate understanding, only the main criterion - i.e., Cost of Maintenance has been taken into consideration; albeit, the procedure would work in the same way even if adding other criteria. The weight of each sub-criteria of CM is taken from the

Table 11. Example of costs of maintenance evaluation between two R\&M methods

\begin{tabular}{|c|c|c|c|c|c|}
\hline $\begin{array}{l}\text { Sub-criteria of Cost of } \\
\text { maintenance }\end{array}$ & $\begin{array}{l}\text { Weight of each } \\
\text { sub-criterion } \\
\text { of Cost of } \\
\text { maintenance }\end{array}$ & $\begin{array}{l}\text { Method directing } \\
\text { towards repairing the } \\
\text { existing ceramic tiling }\end{array}$ & $\begin{array}{l}\text { Score for each } \\
\text { sub-criterion } \\
\text { about repairing }\end{array}$ & $\begin{array}{l}\text { Method directing } \\
\text { towards replacing } \\
\text { existing ceramic tiling } \\
\text { with natural stone } \\
\text { cladding }\end{array}$ & $\begin{array}{l}\text { Score for } \\
\text { each sub- } \\
\text { criterion about } \\
\text { replacement }\end{array}$ \\
\hline $\begin{array}{l}\text { Saving energy } \\
\text { consumption }\end{array}$ & 3 & $\begin{array}{l}\text { Saving } 20 \% \text { of energy } \\
\text { consumption per year }\end{array}$ & 7 & $\begin{array}{l}\text { Saving } 40 \% \text { of energy } \\
\text { consumption per year }\end{array}$ & 9 \\
\hline $\begin{array}{l}\text { Increase the life of } \\
\text { equipment }\end{array}$ & 1 & $\begin{array}{l}\text { Life of equipment } \\
\text { increased by } 23 \text { years }\end{array}$ & 7 & $\begin{array}{l}\text { Life of equipment } \\
\text { increased by } 50 \text { years }\end{array}$ & 10 \\
\hline Efficiency & 2 & $\begin{array}{l}\text { Equivalent Uniform } \\
\text { Annual Cost of } 2.4 € / \mathrm{m}\end{array}$ & 10 & $\begin{array}{l}\text { Equivalent Uniform } \\
\text { Annual Cost of } 3.8 € / \mathrm{m}\end{array}$ & 7 \\
\hline Legal issues & 4 & N.A. & 0 & N.A. & 0 \\
\hline \multicolumn{2}{|l|}{ Total (weight X score) } & \multicolumn{2}{|l|}{48} & \multicolumn{2}{|l|}{51} \\
\hline
\end{tabular}


results shown in Table 7, while the scores' columns report a mark subjectively assigned ranging from 1 (lowest value) to 10 (highest value); the last row, instead, shows the result of the weight column per each score column. From the proposed example, it is possible to derive that the method directing towards replacing the existing ceramic tiling with natural stone cladding is the one chosen by the management of the CB.

Anyway, assigning greater weight to a criterion rather than another seems, from the comparison of this study's results with existing literature, linked with cultural issues. From that, external factors, which have not been considered in this and other studies, are probably those that create differences in the prioritization of criteria. In this regard, cross-country studies are needed to establish these differences and similarities.

\section{Conclusions}

The value added of the proposed research, aimed at classifying and prioritizing criteria for R\&M decisions, is highlighting a sort of homogeneity for the Iranian context; indeed, this and other prior contributions (Amani et al., 2013) seem to underline that the main criterion is the cost of maintenance, in contrast to results for developed countries (Besiktepe et al., 2020) and other developing ones (Sodangi et al., 2014). This result, in practice, substantiates how the choice of the R\&M method is driven by criteria that are prioritized differently, according to the culture in which the organization is embedded.

In terms of practical implications, what this study wants to convey to managers that are responsible for R\&M decisions is: First, managers responsible for R\&M choices should consider R\&M method costs since their initial analysis of the building's construction. The evaluation of these costs must be guided by the principles of sustainable development and must consider the energy embodied in materials and construction, and in both initial and recurring maintenance (see also Mirza, 2006). In order to do that, various methodologies have been elaborated to help budgeting for R\&M activities; they can be categorized into: 1) Plant value methodologies, 2) other formula-based methodologies, 3) life-cycle cost methodologies, and 4) condition assessment methodologies (see Ottoman et al., 1999 for more details). Second, it is hereby recommended (and remarked) that all five categories of criteria are important for R\&M decisions (see also Lavy \& Shohet, 2004). These categories should be systematically considered when making R\&M choices; if the manager does not do so, the adopted R\&M method would lead to overseeing other important variables (e.g., risks) that, if not assessed, can drive to dramatic negative consequences. In doing that, multi-criteria methods should be adopted (see de Almeida, 2001; Parida \& Chattopadhyay, 2007; Shyjith et al., 2008 for some applications). The allocation of a budget for R\&M issues can be managed by a Condition Based Management approach (Shohet, 2003; Straub, 2002), which allows the control of desired maintenance performance levels and, especially, costs (Straub, 2002). This would, indeed, overcome the common problem of poor maintenance performance deriving from the insufficient allocation of maintenance costs (Ali, 2009; Hauash$\mathrm{dh}$ et al., 2020). These tools, as the basis of the cost of maintenance criteria, should be flexible according to the context of implementation. Indeed, managers responsible for the selection of proper R\&M methods should consider that the weights of criteria are likely to be context specific. Hence, it is recommended that future studies examine the effects of the factors (criteria and sub-criteria) in different countries and regions, developed and developing, as well as other sectors of the economy. Other implications for theory come from the implementation of the recent list of factors developed by Lai and Man (2017) and already implemented, with reference to the performance of buildings - but not for maintenance (Lai \& Man, 2018a, 2018b).

There are 3 main limitations of this study. First, it should be recognized that the number of respondents was not very high (i.e., 20), some respondents (i.e., 2) did not have as much work experience as other respondents, and all respondents come from just one developing country, Iran; this calls for other studies that can enhance the generalizability of results looking for a greater number of respondents, with equal work experience, and coming from different developing countries. Second, respondents were chosen through convenience sampling that, despite reducing the complexity of data collection, has the risk of not identifying all the sub-groups of the population. Third, stemming from the fact that criteria have been also selected thanks to the suggestions of the few participants in the Delphi study, they cannot be exhaustive of all the valuable criteria for assessing $R \& M$, due to the fact that they are the product of the perception of experts that can be biased by their socio-demographic characteristics, culture, and cognitive factors. In practice, the selection of these criteria may have suffered from the intrinsic characteristics of the panel - it is worthy of notice, however, that the majority of criteria emerged from the analysis of the literature. It would be interesting to investigate, in a quantitative manner, whether socio-demographic characteristics and/or other psychological variables are significant in the definition and evaluation of criteria for R\&M methods' selection at the individual and group levels.

\section{Author contributions}

Conceptualization, J. T. and H. S.; methodology, H. S. and D. W. M. C.; formal analysis, H. S. and D. W. M. C.; investigation, J. T., H. S.; data curation, H. S.; writing-original draft preparation, H. S. and J. T.; writing-review and editing, M.C. and J. T.; visualization, H. S.; supervision, J. T.; project administration, H. S.

\section{Disclosure statement}

Authors declare that there are not any competing financial, professional, or personal interests from other parties. 


\section{References}

Abu Dabous, S., \& Alkass, S. (2008). Decision support method for multi-criteria selection of bridge rehabilitation strategy. Construction Management and Economics, 26(8), 883-893. https://doi.org/10.1080/01446190802071190

Alani, A. M., Tattersall, R. P., \& Okoroh, M. I. (2002). Quantitative models for building repair and maintenance: a comparative case-study. Facilities, 20(5/6), 176-189. https://doi.org/10.1108/02632770210426666

Al-Arjani, A. H. (2002). Type and size of project influences on number of bidders for maintenance and operation projects in Saudi Arabia. International Journal of Project Management, 20(3), 279-287.

https://doi.org/10.1016/S0263-7863(01)00015-1

Ali, A. S. (2009). Cost decision making in building maintenance practice in Malaysia. Journal of Facilities Management, 7(4), 298-306. https://doi.org/10.1108/14725960910990044

Al-Shammari, M., \& Mili, M. A. (2019). Fuzzy analytic hierarchy process model for customers' bank selection decision in the Kingdom of Bahrain. Operational Research. https://doi.org/10.1007/s12351-019-00496-y

Amani, N., Ali, N. M., Mohammed, A. H., \& Samat, R. A. (2013). Maintenance and management of wastewater system components using the condition index system, prediction process and costs estimation. Eksploatacja i Niezawodność, 15(2), 161-168.

Amani, N., Nasly, M. A., Mohamed, A. H., \& Samat, R. A. (2012). A survey on the implementation of facilities maintenance management system of building in Iran. Malaysian Journal of Civil Engineering, 24(1), 85-95.

Au-Yong, C. P., Ali, A. S., Ahmad, F., \& Chua, S. J. (2017). Influences of key stakeholders' involvement in maintenance management. Property Management, 35(2), 217-231. https://doi.org/10.1108/PM-01-2016-0004

Bagaeen, S. (2007). Brand Dubai: the instant city; or the instantly recognizable city. International Planning Studies, 12(2), 173197. https://doi.org/10.1080/13563470701486372

Bahriny, F., \& Bell, S. (2020). Patterns of urban park use and their relationship to factors of quality: a case study of Tehran, Iran. Sustainability, 12(4), 1560. https://doi.org/10.3390/su12041560

Baum, A. (2009). Commercial real estate investment. Taylor \& Francis. https://doi.org/10.4324/9780080963662

Besiktepe, D., Ozbek, M. E., \& Atadero, R. A. (2020). Identification of the criteria for building maintenance decisions in facility management: first step to developing a multi-criteria decision-making approach. Buildings, 10(9), 166. https://doi.org/10.3390/buildings10090166

Bevilacqua, M., \& Braglia, M. (2000). The analytic hierarchy process applied to maintenance strategy selection. Reliability Engineering \& System Safety, 70(1), 71-83. https://doi.org/10.1016/S0951-8320(00)00047-8

Bond, S. A., Hwang, S., Lin, Z., \& Vandell, K. D. (2007). Marketing period risk in a portfolio context: theory and empirical estimates from the UK commercial real estate market. The Journal of Real Estate Finance and Economics, 34(4), 447-461. https://doi.org/10.1007/s11146-007-9022-1

Boussabaine, A. H., \& Kirkham, R. J. (2004). Simulation of maintenance costs in UK local authority sport centres. Construction Management and Economics, 22(10), 1011-1020. https://doi.org/10.1080/1466433X.2004.11878565

Braun, V., \& Clarke, V. (2006). Using thematic analysis in psychology. Qualitative Research in Psychology, 3(2), 77-101. https://doi.org/10.1191/1478088706qp063oa
Chan, D. W. M., \& Chan, J. H. L. (2012). Developing a performance measurement index (PMI) for target cost contracts in construction: a Delphi study. Construction Law Journal, 28(8), 590-613.

Chandrahas, Mishra, S. K., \& Mahapatra, D. (2015). Maintenance strategy and decision making - AHP method. International Journal of Advanced Engineering Research and Studies, IV(II), 256-258.

Chang, D. Y. (1996). Applications of the extent analysis method on fuzzy AHP. European Journal of Operational Research, 95(3), 649-655. https://doi.org/10.1016/0377-2217(95)00300-2

Christudason, A., Kenna, P., \& Lujanen, M. (2010). Legal challenges in ensuring regular maintenance and repairs of owneroccupied apartment blocks. International Journal of Law in the Built Environment, 2(2), 178-197.

https://doi.org/10.1108/17561451011058807

Chua, S. J. L., Ali, A. S., \& Alias, A. (2014). Procurement method selection for building maintenance projects: the case of Malaysian public universities. World Journal of Engineering and Technology, 2(3), 7-13. https://doi.org/10.4236/wjet.2014.23B002

Dabiri, M., Oghabi, M., Sarvari, H., Sabeti, M., \& Kashefi, H. (2020). A combination risk-based approach to post-earthquake temporary accommodation site selection: a case study in Iran. Iranian Journal of Fuzzy Systems, 17(6), 54-74.

Daibing, W., \& Zeng, T. (2014). BIM in the commercial real estate project operation and maintenance management of applied research. Housing Science, 3, 17.

de Almeida, A. T. (2001). Multicriteria decision making on maintenance: spares and contracts planning. European Journal of Operational Research, 129(2), 235-241. https://doi.org/10.1016/S0377-2217(00)00220-4

De Silva, N., Ranasinghe, M., \& De Silva, C. R. (2012). Risk factors affecting building maintenance under tropical conditions. Journal of Financial Management of Property and Construction, 17(3), 235-252. https://doi.org/10.1108/13664381211274353

Deng, H. (1999). Multicriteria analysis with fuzzy pairwise comparison. International Journal of Approximate Reasoning, 21, 215-231. https://doi.org/10.1016/S0888-613X(99)00025-0

Duca, J. V., \& Ling, D. C. (2020). The other (commercial) real estate boom and bust: the effects of risk premia and regulatory capital arbitrage. Journal of Banking \& Finance, 112, 105317. https://doi.org/10.1016/j.jbankfin.2018.03.006

ElSorady, D. A., \& Rizk, S. M. (2020). LEED v4.1 operations and maintenance for existing buildings and compliance assessment: Bayt Al-Suhaymi, historic Cairo. Alexandria Engineering Journal, 59(1), 519-531.

https://doi.org/10.1016/j.aej.2020.01.027

Fadavi-Ghaffari, M., Azad, A., Shariatzadeh, H., Taghizadeh, G., \& Aminizadeh, S. (2017). Translation, cultural adaptation, face and content validity of the Persian version "Patient-rated wrist evaluation" (PRWE-Persian) questionnaire. Journal of Modern Rehabilitation, 11(1), 51-62. https://doi.org/10.18869/nirp.jmr.11.1.51

Ferreira, C., Silva, A., de Brito, J., Dias, I. S., \& Flores-Colen, I. (2021). The impact of imperfect maintenance actions on the degradation of buildings' envelope components. Journal of Building Engineering, 33, 101571. https://doi.org/10.1016/j.jobe.2020.101571

Flores-Colen, I., \& de Brito, J. (2010). A systematic approach for maintenance budgeting of buildings façades based on predictive and preventive strategies. Construction and Building Materials, 24(9), 1718-1729. https://doi.org/10.1016/j.conbuildmat.2010.02.017 
Galar, D., Parida, A., Kumar, U., Stenström, C., \& Berges, L. (2011). Maintenance metrics: a hierarchical model of balanced scorecard. In 2011 IEEE International Conference on Quality and Reliability (pp. 67-74). IEEE. https://doi.org/10.1109/ICQR.2011.6031683

Geltner, D., Miller, N. G., Clayton, J., \& Eichholtz, P. (2001). Commercial real estate analysis and investments (Vol. 1). South-Western.

Ghazali, Z., Lim, M. R. T., \& Jamak, A. B. S. (2019). Maintenance performance improvement analysis using fuzzy Delphi method: a case of an international lube blending plant in Malaysia. Journal of Quality in Maintenance Engineering, 25(1), 162-180. https://doi.org/10.1108/JQME-11-2016-0058

Ghent, A. C., Torous, W. N., \& Valkanov, R. I. (2019). Commercial real estate as an asset class. Annual Review of Financial Economics, 11, 153-171.

https://doi.org/10.1146/annurev-financial-110118-123121

Ghosh, D., \& Roy, S. (2010). A decision-making framework for process plant maintenance. European Journal of Industrial Engineering, 4(1), 78-98.

https://doi.org/10.1504/EJIE.2010.029571

Grussing, M. N. (2014). Life cycle asset management methodologies for buildings. Journal of Infrastructure Systems, 20(1), 04013007.

https://doi.org/10.1061/(ASCE)IS.1943-555X.0000157

Häkkinen, T., \& Belloni, K. (2011). Barriers and drivers for sustainable building. Building Research \& Information, 39(3), 239-255. https://doi.org/10.1080/09613218.2011.561948

Hauashdh, A., Jailani, J., \& Rahman, I. A. (2020). Building maintenance practices in Malaysia: a systematic review of issues, effects and the way forward. International Journal of Building Pathology and Adaptation, 38(5), 653-672.

https://doi.org/10.1108/IJBPA-10-2019-0093

Hon, C. K. H., Chan, A. P. C., \& Chan, D. W. M. (2011). Strategies for improving safety performance of repair, maintenance, minor alteration and addition (RMAA) works. Facilities, 29(13/14), 591-610.

https://doi.org/10.1108/02632771111178391

Hon, C. K. H., Chan, A. P. C., \& Yam, M. C. H. (2012). Empirical study to investigate the difficulties of implementing safety practices in the repair and maintenance sector in Hong Kong. Journal of Construction Engineering and Management, 138(7), $877-884$.

https://doi.org/10.1061/(ASCE)CO.1943-7862.0000497

Hsu, C. C., \& Sandford, B. A. (2007). The Delphi technique: making sense of consensus. Practical Assessment, Research, and Evaluation, 12(1), 10.

Johnson, E. (2013). Face validity. In F. R. Volkmar (Ed.), Encyclopedia of autism spectrum disorders. Springer.

Katebi, A., \& Almasian, F. (2016). Review of maintenance strategies in construction projects [Conference presentation]. Proceedings of the Third International Conference on Civil Engineering, Architecture and Structures, Norway.

Khoshfetrat, R., Sarvari, H., Chan, D. W. M., \& Rakhshanifar, M. (2020). Critical risk factors for implementing building information modelling (BIM): a Delphi-based survey. International Journal of Construction Management, 1-10. https://doi.org/10.1080/15623599.2020.1788759

Khosravi, M., Sarvari, H., Chan, D. W. M., Cristofaro, M., \& Chen, Z. (2020). Determining and assessing the risks of commercial and recreational complex building projects in developing countries: a survey of experts in Iran. Journal of Facilities Management, 18(3), 259-282. https://doi.org/10.1108/JFM-02-2020-0010
Kim, S., Jang, Y., Shin, Y., \& Kim, G. (2014). Economic feasibility analysis of the application of geothermal energy facilities to public building structures. Sustainability, 6(4), 1667-1685. https://doi.org/10.3390/su6041667

Kizim, A. V. (2013). Establishing the maintenance and repair body of knowledge: comprehensive approach to ensuring equipment maintenance and repair organization efficiency. Original Research Article Procedia Technology, 9, 812-818. https://doi.org/10.1016/j.protcy.2013.12.090

Lai, J. H. (2010). Operation and maintenance budgeting for commercial buildings in Hong Kong. Construction Management and Economics, 28(4), 415-427.

https://doi.org/10.1080/01446190903365665

Lai, J. H. (2011). Comparative evaluation of facility management services for housing estates. Habitat International, 35, 391-397. https://doi.org/10.1016/j.habitatint.2010.11.009

Lai, J. H. (2015). Maintenance performance: examination of the computer-aided maintenance data of a large commercial building. Journal of Performance of Constructed Facilities, 29(4), 4014118. https://doi.org/10.1061/(ASCE)CF.19435509.0000619

Lai, J. H., \& Man, C. S. (2017). Developing a performance evaluation scheme for engineering facilities in commercial buildings: state-of-the-art review. International Journal of Strategic Property Management, 21(1), 41-57. https://doi.org/10.3846/1648715X.2016.1247304

Lai, J. H., \& Man, C. S. (2018a). Performance indicators for facilities operation and maintenance (Part 1): systematic classification and mapping. Facilities, 36(9/10), 476-494. https://doi.org/10.1108/F-08-2017-0075

Lai, J. H., \& Man, C. S. (2018b). Performance indicators for facilities operation and maintenance (Part 2): shortlisting through a focus group study. Facilities, 36(9/10), 495-509. https://doi.org/10.1108/F-08-2017-0076

Lai, J. H., Yik, F. W., \& Chan, A. K. (2009). Maintenance cost of chiller plants in Hong Kong. Building Services Engineering Research and Technology, 30(1), 65-78. https://doi.org/10.1177/0143624408096290

Lai, J. H., Yik, F. W., \& Jones, P. (2004). Disputes arising from vaguely defined contractual responsibilities in building services maintenance contracts. Facilities, 22(1/2), 44-52. https://doi.org/10.1108/02632770410517942

Lai, J. H., Yik, F. W., \& Jones, P. (2006). Critical contractual issues of outsourced operation and maintenance service for commercial buildings. International Journal of Service Industry Management, 17(4), 320-343.

https://doi.org/10.1108/09564230610680640

Lai, J., Yik, F., \& Jones, P. (2008). Expenditure on operation and maintenance service and rental income of commercial buildings. Facilities, 26(5/6), 242-265.

https://doi.org/10.1108/02632770810865014

Lam, E. W. M., Chan, A. P. C., \& Chan, D. W. M. (2010). Benchmarking success of building maintenance projects. Facilities, 28(5/6), 290-305. https://doi.org/10.1108/02632771011031529

Lateef, O. A. (2009). Building maintenance management in Malaysia. Journal of Building Appraisal, 4(3), 207-214. https://doi.org/10.1057/jba.2008.27

Lavy, S., \& Bilbo, D. L. (2009). Facilities maintenance management practices in large public schools, Texas. Facilities, 27(1/2), 5-20. https://doi.org/10.1108/02632770910923054

Lavy, S., \& Shohet, I. M. (2004). Integrated maintenance management of hospital buildings: a case study. Construction Management and Economics, 22(1), 25-34. https://doi.org/10.1080/0144619042000186031 
Lavy, S., \& Shohet, I. M. (2007). On the effect of service life conditions on the maintenance costs of healthcare facilities. Construction Management and Economics, 25(10), 1087-1098. https://doi.org/10.1080/01446190701393034

Ledford, A. K., \& Lynch, S. M. (2019). Comparing theories of resource distribution: the case of Iran. Socius, 5. https://doi.org/10.1177/2378023119886406

Lee, C. K., \& Kim, S. K. (2007). GA-based algorithm for selecting optimal repair and rehabilitation methods for reinforced concrete (RC) bridge decks. Automation in Construction, 16(2), 153-164. https://doi.org/10.1016/j.autcon.2006.03.001

Lee, H. H. Y., \& Scott, D. (2009). Overview of maintenance strategy, acceptable maintenance standard and resources from a building maintenance operation perspective. Journal of Building Appraisal, 4(4), 269-278.

https://doi.org/10.1057/jba.2008.46

Liddle, J., Bowser, J., Ilic, B., \& Luciani, V. (2020). So, you want to have a NanoFab? Shared-use nanofabrication and characterization facilities: cost-of-ownership, toolset, utilization, and lessons learned. Journal of Research of the National Institute of Standards and Technology, 125, 125009. https://doi.org/10.6028/jres.125.009

Lind, H., \& Muyingo, H. (2012). Building maintenance strategies: planning under uncertainty. Property Management, 30(1), 14-28. https://doi.org/10.1108/02637471211198152

López, J., Pérez, D., Paz, E., \& Santana, A. (2013). A building maintenance and surveillance system based on autonomous robots. Robotics and Autonomous Systems, 61(12), 1559-1571. https://doi.org/10.1016/j.robot.2013.06.012

Mangano, G., \& De Marco, A. (2014). The role of maintenance and facility management in logistics: a literature review. Facilities, 32(5/6), 241-255. https://doi.org/10.1108/F-08-2012-0065

Martínez, L. B., Márquez, A. C., Gunckel, P. V., \& Andreani, A. A. (2013). The graphical analysis for maintenance management method: a quantitative graphical analysis to support maintenance management decision making. Quality and Reliability Engineering International, 29(1), 77-87. https://doi.org/10.1002/qre.1296

Mirza, S. (2006). Durability and sustainability of infrastructure a state-of-the-art report. Canadian Journal of Civil Engineering, 33(6), 639-649. https://doi.org/10.1139/106-049

Motamed, P., \& Majrouhi, J. (2018). A framework to select the best strategy for Iran's entry into the repair and maintenance market of oil drilling rigs. Civil Engineering Journal, 4(11), 2702-2718. https://doi.org/10.28991/cej-03091193

Motawa, I., \& Almarshad, A. (2013). A knowledge-based BIM system for building maintenance. Automation in Construction, 29, 173-182. https://doi.org/10.1016/j.autcon.2012.09.008

Munir, M., Kiviniemi, A., Finnegan, S., \& Jones, S. W. (2019). BIM business value for asset owners through effective asset information management. Facilities, 38(3/4), 181-200. https://doi.org/10.1108/F-03-2019-0036

Nourelfath, M., Nahas, N., \& Ben-Daya, M. (2016). Integrated preventive maintenance and production decisions for imperfect processes. Reliability Engineering and System Safety, 148, 21-31. https://doi.org/10.1016/j.ress.2015.11.015

Olanrewaju, A. L., \& Abdul-Aziz, A. R. (2014). Building maintenance processes and practices: the case of a fast developing country. Springer. https://doi.org/10.1007/978-981-287-263-0

Olawumi, T. O., \& Chan, D. W. M. (2018). Identifying and prioritizing the benefits of integrating BIM and sustainability practices in construction projects: a Delphi survey of international experts. Sustainable Cities and Society, 40, 16-27. https://doi.org/10.1016/j.scs.2018.03.033
Oprea, L., \& Popescu, V. (2008). Challenges and methodologies in transmission planning for mega-cities. In MELECON 2008 - The 14th IEEE Mediterranean Electrotechnical Conference (pp. 726-731). IEEE. https://doi.org/10.1109/MELCON.2008.4618521

Ottoman, G. R., Nixon, W. B., \& Lofgren, S. T. (1999). Budgeting for facility maintenance and repair. I: methods and models. Journal of Management in Engineering, 15(4), 71-83. https://doi.org/10.1061/(ASCE)0742-597X(1999)15:4(71)

Parida, A., \& Chattopadhyay, G. (2007). Development of a multicriteria hierarchical framework for maintenance performance measurement (MPM). Journal of Quality in Maintenance Engineering, 13(3), 241-258. https://doi.org/10.1108/13552510710780276

Pezshki, Z. M., Shadman, A., Alizadeh, M., Hakimi, S., \& Heidari, F. (2017). Validity and reliability of the questionnaire for assessing women's reproductive history in Azar cohort study. Journal of Caring Sciences, 6(2), 185-188. https://doi.org/10.15171/jcs.2017.018

Pivo, G., \& Fisher, J. D. (2011). The walkability premium in commercial real estate investments. Real Estate Economics, 39(2), 185-219. https://doi.org/10.1111/j.1540-6229.2010.00296.x

Pourjavad, E., Shirouyehzad, H., \& Shahin, A. (2013). Selecting maintenance strategy in mining industry by analytic network process and TOPSIS. International Journal of Industrial and Systems Engineering, 15(2), 171-192.

https://doi.org/10.1504/IJISE.2013.056095

Preedy, V. R. (2010). Content validity. In V. R. Preedy, \& Watson, R. R. (Eds.), Handbook of disease burdens and quality of life measures. Springer. https://doi.org/10.1007/978-0-387-78665-0_5383

Re Cecconi, F., Moretti, N., \& Dejaco, M. C. (2019). Measuring the performance of assets: a review of the facility condition index. International Journal of Strategic Property Management, 23(3), 187-196. https://doi.org/10.3846/ijspm.2019.7955

Ruparathna, R., Hewage, K., \& Sadiq, R. (2018). Multi-period maintenance planning for public buildings: a risk-based approach for climate conscious operation. Journal of Cleaner Production, 170, 1338-1353.

https://doi.org/10.1016/j.jclepro.2017.09.178

Saaty, T. L. (1972). An eigenvalue allocation model for prioritization and planning. Energy management and policy center (Working paper, pp. 28-31). University of Pennsylvania.

Sadeghi, M., Elliott, J. W., Porro, N., \& Strong, K. (2019). Developing building information models (BIM) for building handover, operation and maintenance. Journal of Facilities Management, 17(3), 301-316. https://doi.org/10.1108/JFM-04-2018-0029

Sayed, A. Y. A., Seth, D., \& Hamouda, A. M. S. (2019). Prioritisation of lean construction barriers in Qatari context: a fuzzy AHP approach. International Journal of Business Excellence, 19(4), 503-531. https://doi.org/10.1504/IJBEX.2019.103456

Sarvari, H., Chan, D. W. M., Banaitiene, N., Noor, N. M., \& Beer, M. (2021). Barriers to development of private sector investment in water and sewage industry. Built Environment Project and Asset Management, 11(1), 52-70.

https://doi.org/10.1108/BEPAM-11-2019-0110

Sarvari, H., Cristofaro, M., Chan, D. W. M., Noor, N. M., \& Amini, M. (2020). Completing abandoned public facility projects by the private sector: results of a Delphi survey in the Iranian Water and Wastewater Company. Journal of Facilities Management, 18(5), 547-566. https://doi.org/10.1108/JFM-07-2020-0046 
Sarvari, H., Rakhshanifar, M., Tamošaitienė, J., Chan, D. W. M., \& Beer, M. (2019). A risk based approach to evaluating the impacts of Zayanderood drought on sustainable development indicators of riverside urban in Isfahan-Iran. Sustainability, 11(23), 6797. https://doi.org/10.3390/su11236797

Shafiee, M. (2015). Maintenance strategy selection problem: an MCDM overview. Journal of Quality in Maintenance Engineering, 21(4), 378-402.

https://doi.org/10.1108/JQME-09-2013-0063

Shen, G. Q. P. (1997). A comparative study of priority setting methods for planned maintenance of public buildings. Facilities, 15(12/13), 331-339.

https://doi.org/10.1108/02632779710188324

Shyjith, K., Ilangkumaran, M., \& Kumanan, S. (2008). Multi-criteria decision-making approach to evaluate optimum maintenance strategy in textile industry. Journal of Quality in Maintenance Engineering, 14(4), 375-386.

https://doi.org/10.1108/13552510810909975

Shohet, I. M. (2003). Building evaluation methodology for setting maintenance priorities in hospital buildings. Construction Management and Economics, 21(7), 681-692. https://doi.org/10.1080/0144619032000115562

Shohet, I. M., \& Nobili, L. (2016a). Performance-based maintenance of public facilities: principles and implementation in courthouses. Journal of Performance of Constructed Facilities, 30(4), 04015086.

https://doi.org/10.1061/(ASCE)CF.1943-5509.0000835

Shohet, I. M., \& Nobili, L. (2016b). Enterprise resource planning system for performance-based-maintenance of clinics. Automation in Construction, 65, 33-41.

https://doi.org/10.1016/j.autcon.2016.01.008

Shohet, I. M., \& Nobili, L. (2017). Application of key performance indicators for maintenance management of clinics facilities. International Journal of Strategic Property Management, 21(1), 58-71. https://doi.org/10.3846/1648715X.2016.1245684

Shohet, I. M., \& Perelstein, E. (2004). Decision support model for the allocation of resources in rehabilitation projects. Journal of Construction Engineering and Management, 130(2), 249-257. https://doi.org/10.1061/(ASCE)0733-9364(2004)130:2(249)

Shohet, I. M., \& Straub, A. (2013). Performance-based-maintenance: a comparative study between the Netherlands and Israel. International Journal of Strategic Property Management, 17(2), 199-209.

https://doi.org/10.3846/1648715X.2013.807482

Shohet, I. M., Lavy-Leibovich, S., \& Bar-On, D. (2003). Integrated maintenance monitoring of hospital buildings. Construction Management and Economics, 21(2), 219-228. https://doi.org/10.1080/0144619032000079734

Sodangi, M., Khamdi, M. F., Idrus, A., Hammad, D. B., \& AhmedUmar, A. (2014). Best practice criteria for sustainable maintenance management of heritage buildings in Malaysia. Procedia Engineering, 77, 11-19.

https://doi.org/10.1016/j.proeng.2014.07.017

Straub, A. (2002). Strategic technical management of housing stock: lessons from Dutch housing associations. Building Research and Information, 30(5), 372-381.

https://doi.org/10.1080/09613210210150955

Suganthi, L. (2018). Multi expert and multi criteria evaluation of sectoral investments for sustainable development: an in- tegrated fuzzy AHP, VIKOR/DEA methodology. Sustainable Cities and Society, 43, 144-156.

https://doi.org/10.1016/j.scs.2018.08.022

Suweero, K., Moungnoi, W., \& Charoenngam, C. (2017). Outsourcing decision factors of building operation and maintenance services in the commercial sector. Property Management, 35(3), 254-274.

https://doi.org/10.1108/PM-06-2016-0028

Taber, K. S. (2018). The use of Cronbach's alpha when developing and reporting research instruments in science education. Research in Science Education, 48, 1273-1296. https://doi.org/10.1007/s11165-016-9602-2

Tamošaitienė, J., Sarvari, H., Chan, D. W. M., \& Cristofaro, M. (2021). Assessing the barriers and risks to private sector participation in infrastructure construction projects in developing countries of Middle East. Sustainability, 13(1), 153. https://doi.org/10.3390/su13010153

Thaheem, M. J., \& De Marco, A. (2014). Sustainable repair \& maintenance of buildings in the developing countries: a risk management perspective and proposal of customized framework. Journal of Civil Engineering and Architecture Research, 1(1), 14-23.

Thengane, S. K. (2019). Assessment of different technologies for managing yard waste using analytic hierarchy process. Process Integration and Optimization for Sustainability, 3, 255-272. https://doi.org/10.1007/s41660-018-0070-1

United Nations. (2020). World economic situation prospects. https://www.un.org/development/desa/dpad/wp-content/uploads/sites/45/WESP2020_Annex.pdf

Vanier, D., Tesfamariam, S., Sadiq, R., \& Lounis, Z. (2006, June 14-16). Decision models to prioritize maintenance and renewal alternatives. In Joint International Conference on Computing and Decision Making in Civil and Building Engineering (pp. 2594-2603), Montréal, QC.

Wall, D. M. (1993). Building maintenance in the context of developing countries. Construction Management and Economics, 11(3), 186-193. https://doi.org/10.1080/01446199300000018

Wieczorek, D., Plebankiewicz, E., \& Zima, K. (2019). Model estimation of the whole life cost of a building with respect to risk factors. Technological and Economic Development of Economy, 25(1), 20-38. https://doi.org/10.3846/tede.2019.7455

Yousefli, Z., Nasiri, F., \& Moselhi, O. (2020). Maintenance workflow management in hospitals: an automated multi-agent facility management system. Journal of Building Engineering, 32, 101431. https://doi.org/10.1016/j.jobe.2020.101431

Yuan, J., Li, W., Xia, B., Chen, Y., \& Skibniewski, M. J. (2019). Operation performance measurement of public rental housing delivery by PPPS with fuzzy-AHP comprehensive evaluation. International Journal of Strategic Property Management, 23(5), 328-353. https://doi.org/10.3846/ijspm.2019.9820

Zavadskas, E. K., Turskis, Z., \& Kildienė, S. (2014). State of art surveys of overviews on MCDM/MADM methods. Technological and Economic Development of Economy, 20, 165-179. https://doi.org/10.3846/20294913.2014.892037

Zawawi, E. M. A., \& Kamaruzzaman, S. N. (2009). Personnel characteristics of maintenance practice: a case of high-rise office buildings in Malaysia. Journal of Sustainable Development, 2(1), 111. https://doi.org/10.5539/jsd.v2n1p111 